\title{
Emerging proteomic biomarkers of X-linked muscular dystrophy
}

Paul Dowling, Sandra Murphy, Margit Zweyer, Maren Raucamp, Dieter Swandulla \& Kay Ohlendieck

To cite this article: Paul Dowling, Sandra Murphy, Margit Zweyer, Maren Raucamp, Dieter Swandulla \& Kay Ohlendieck (2019) Emerging proteomic biomarkers of X-linked muscular dystrophy, Expert Review of Molecular Diagnostics, 19:8, 739-755, DOI: 10.1080/14737159.2019.1648214

To link to this article: https://doi.org/10.1080/14737159.2019.1648214

曲 Published online: 02 Aug 2019.

Submit your article to this journal

Џll Article views: 667

Q View related articles $\square$

View Crossmark data $\asymp$

4 Citing articles: 6 View citing articles 준 


\title{
Emerging proteomic biomarkers of X-linked muscular dystrophy
}

\author{
Paul Dowling ${ }^{\mathrm{a}, \mathrm{b}}$, Sandra Murphy ${ }^{\mathrm{c}}$, Margit Zweyer ${ }^{\mathrm{d}}$, Maren Raucamp ${ }^{\mathrm{d}}$, Dieter Swandulla ${ }^{\mathrm{d}}$ and Kay Ohlendieck ${ }^{\mathrm{a}, \mathrm{b}}$

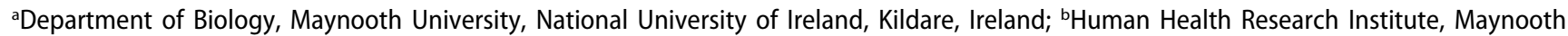 \\ University, Kildare, Ireland; 'Newcastle Fibrosis Research Group, Institute of Cellular Medicine, Faculty of Medical Sciences, Newcastle University, \\ Newcastle upon Tyne, UK; dinstitute of Physiology II, University of Bonn, Bonn, Germany
}

\begin{abstract}
Introduction: Progressive skeletal muscle wasting is the manifesting symptom of Duchenne muscular dystrophy, an X-linked inherited disorder triggered by primary abnormalities in the DMD gene. The almost complete loss of dystrophin isoform Dp427 causes a multi-system pathology that features in addition to skeletal muscle weakness also late-onset cardio-respiratory deficiencies, impaired metabolism and abnormalities in the central nervous system.

Areas covered: This review focuses on the mass spectrometry-based proteomic characterization of $X$-linked muscular dystrophy with special emphasis on the identification of novel biomarker candidates in skeletal muscle tissues, as well as non-muscle tissues and various biofluids. Individual sections focus on molecular and cellular aspects of the pathogenic changes in dystrophinopathy, proteomic workflows used in biomarker research, the proteomics of the dystrophin-glycoprotein complex and the potential usefulness of newly identified protein markers involved in fibre degeneration, fibrosis and inflammation. Expert opinion: The systematic application of large-scale proteomic surveys has identified a distinct cohort of both tissue- and biofluid-associated protein species with considerable potential for improving diagnostic, prognostic and therapy-monitoring procedures. Novel proteomic markers include components involved in fibre contraction, cellular signalling, ion homeostasis, cellular stress response, energy metabolism and the immune response, as well as maintenance of the cytoskeletal and extracellular matrix.
\end{abstract}

ARTICLE HISTORY

Received 7 June 2019

Accepted 23 July 2019

KEYWORDS

Biofluid; biomarker;

Duchenne muscular

dystrophy;

dystrophinopathy; liquid biopsy; muscle biopsy

\section{Introduction}

Progressive forms of inherited or acquired human disorders that are associated with primary or secondary skeletal muscle wasting are characterized by loss of contractile strength and decreased adaptability to changed physical demands [1]. These neuromuscular symptoms can have a devastating impact on the quality of life, especially muscular disorders of early childhood [2]. In primary diseases of the skeletal musculature, functional deficiencies in contractile tissues are often accompanied by alterations in cellular signalling mechanisms, physiological homeostasis, energy metabolism and fibre type distribution [3]. The most frequently inherited neuromuscular disorder of early childhood is Duchenne muscular dystrophy, which is associated with a substantial economic and caregiver burden [4]. X-linked muscular dystrophy is a mono-genetic disorder due to primary abnormalities in the largest human gene, the Xp21-located and 79-exon spanning DMD gene [5]. This highly complex gene encodes proteins ranging from approximately 71 to $427 \mathrm{kDa}$ whereby the alternative usage of seven promoters, which are linked to unique first exons, is the basis of the tissue-specific production of a variety of distinct transcripts and corresponding protein products [6], as outlined in Figure 1. The full-length Dp427-M isoform of dystrophin belongs to the class of giant muscle proteins, which have been extensively characterized by biochemical and mass spectrometric analyses [7].
Skeletal muscle dystrophin is located in the subsarcolemmal cytoskeleton in voluntary contractile fibres and contains aminoterminal and central actin-binding domains, multiple spectrin repeats and a unique carboxy-terminal dystroglycan binding domain [5]. The most progressive form of dystrophinopathy is related to a great variety of patient-specific mutations, including mostly large deletions or duplications, but also small deletions, small insertions, splice site mutations, point mutations and mid-intronic mutations [8]. These genetic abnormalities result in the almost complete loss of the Dp427-M isoform and cause a multi-system pathology that primarily affects the skeletal musculature, but is also characterised by severe secondary dysfunctions in the cardio-respiratory system, the central nervous system and metabolism, as well as accompanying complications due to scoliosis [9]. Ideally, a panel of robust and highly sensitive biomarkers would be available to evaluate the various clinical features of dystrophinopathy and improve differential diagnostic, prognostic and therapy-monitoring procedures.

A variety of non-proteinaceous biomarker candidates of muscular dystrophy, such as single nucleotide polymorphisms, lipids, metabolites and extracellular microRNAs [10], as well as skeletal muscle imaging technologies [11], have been evaluated and shown considerable potential to improve diagnostics [12]. Building on previous reviews on the usage of mass spectrometric techniques in muscular dystrophy research 


\section{Article Highlights}

- Duchenne muscular dystrophy is a highly complex multi-system disorder that is characterized by chronic skeletal muscle wasting

- Mass spectrometry-based proteomics has identified new biomarker candidates of dystrophinopathy

- Novel proteomic biomarkers include tissue-associated proteins involved in a large variety of cellular processes.

- New biofluid-associated biomarkers have a great potential for establishing superior diagnostic methods in the field of muscular dystrophy.

- Promising new biomarker candidates include titin fragments in urine and a variety of increased muscle proteins in serum, such as fibronectin, carbonic anhydrase, myosin light chain, haptoglobin, fatty acid binding proteins, myomesin and troponin.

- Newly identified biomarkers of muscular dystrophy have now to be established in clinical laboratory practice

- Robust biomarkers may then be useful for the improved evaluation of new treatment approaches, such as stem cell transfer or gene therapy.

[13-15], this article focuses on emerging proteomic biomarkers of X-linked muscular dystrophy. General background information is based on established publications on the dystrophin-glycoprotein complex and muscular dystrophy. Literature screening was carried out with the Pubmed database and focused on mass spectrometry-based proteomic studies using combinations of a variety of search terms, i.e. 'proteomics', 'mass spectrometry', 'Duchenne muscular dystrophy', 'dystrophinopathy', 'dystrophin', 'dystrophinglycoprotein complex', 'diagnosis' 'prognosis' 'therapy' and 'biomarker'. Publications were then further screened for their suitability based on the specific topic of this review, taking into account the suggested total number of references.

Major findings on novel proteomic biomarker candidates associated with skeletal muscle tissues, non-skeletal muscle tissues and various biofluids and their potential relevance to improve molecular diagnostics are discussed in individual sections. Illustrative figures are presented to summarize the complex pathology of X-linked muscular dystrophy, the bioanalytical workflow for the identification of novel disease markers using mass spectrometry, the proteomic characterization of the wider dystrophin-associated protein complex and the biochemical diversity of recently identified proteomic biomarker candidates of chronic fibre degeneration, reactive myofibrosis and sterile inflammation. A summary of the main findings from proteomic studies that have focused on the identification of the dystrophin complex and biomarker discovery in dystrophic skeletal muscles, secondarily affected non-skeletal muscle tissues and biological fluids are listed in individual tables. A certain degree of overlap exists between these listings due to the fact that some proteomic investigations have been concerned with both the basic biochemical characterization of dystrophin complexes and the comparative analysis of dystrophic tissues.

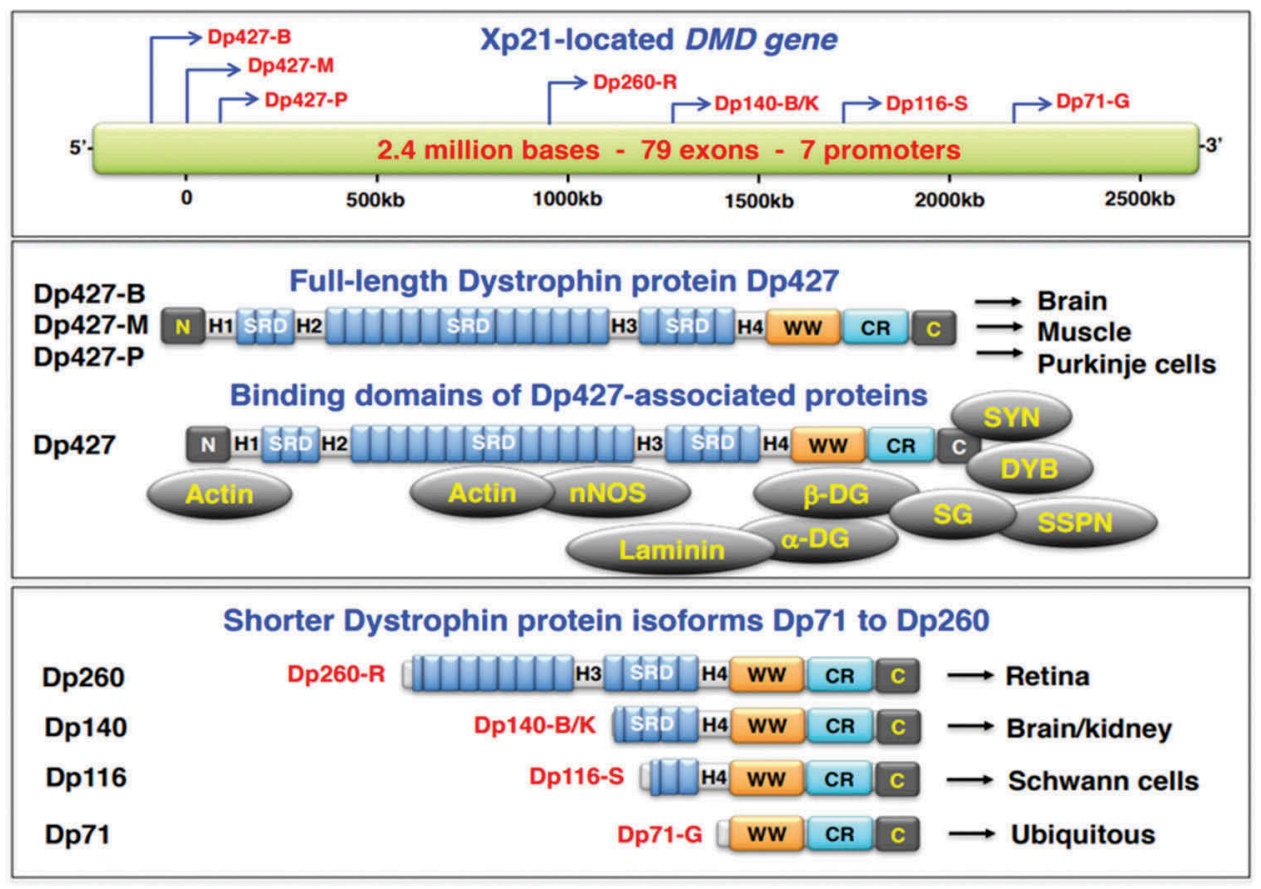

Figure 1. Schematic presentation of the DMD gene with tissue-specific promoters and domain structure of dystrophin protein isoforms. Shown is the overall organization of the dystrophin gene, which represents the largest gene in the human genome and contains 7 different promoters for the tissue-specific expression of full-length dystrophin isoforms Dp427-B (brain), Dp427-M (muscle) and Dp427-P (Purkinje cells), as well as the shorter dystrophin isoforms Dp260-R (retina), Dp140-B/K (brain/kidney), Dp116-S (Schwann cells in peripheral nerves) and Dp71-G (ubiquitous). The dystrophin protein products are characterized by a highly complex domain structure within tissue-specific protein isoforms. The diagram provides information on Dp427-associated domains for direct interactions with dystrophin-binding proteins, such as $\beta$-dystroglycan ( $\beta$-DG), neuronal nitric oxide synthase (nNOS), syntrophins (SYN) and dystrobrevins (DYB). Indirectly associated proteins belonging to the core dystrophin-glycoprotein complex are also marked, including a-dystroglycan ( $\alpha-D G)$, sarcoglycans (SG), sarcospan (SSPN), laminin and cortical actin. 


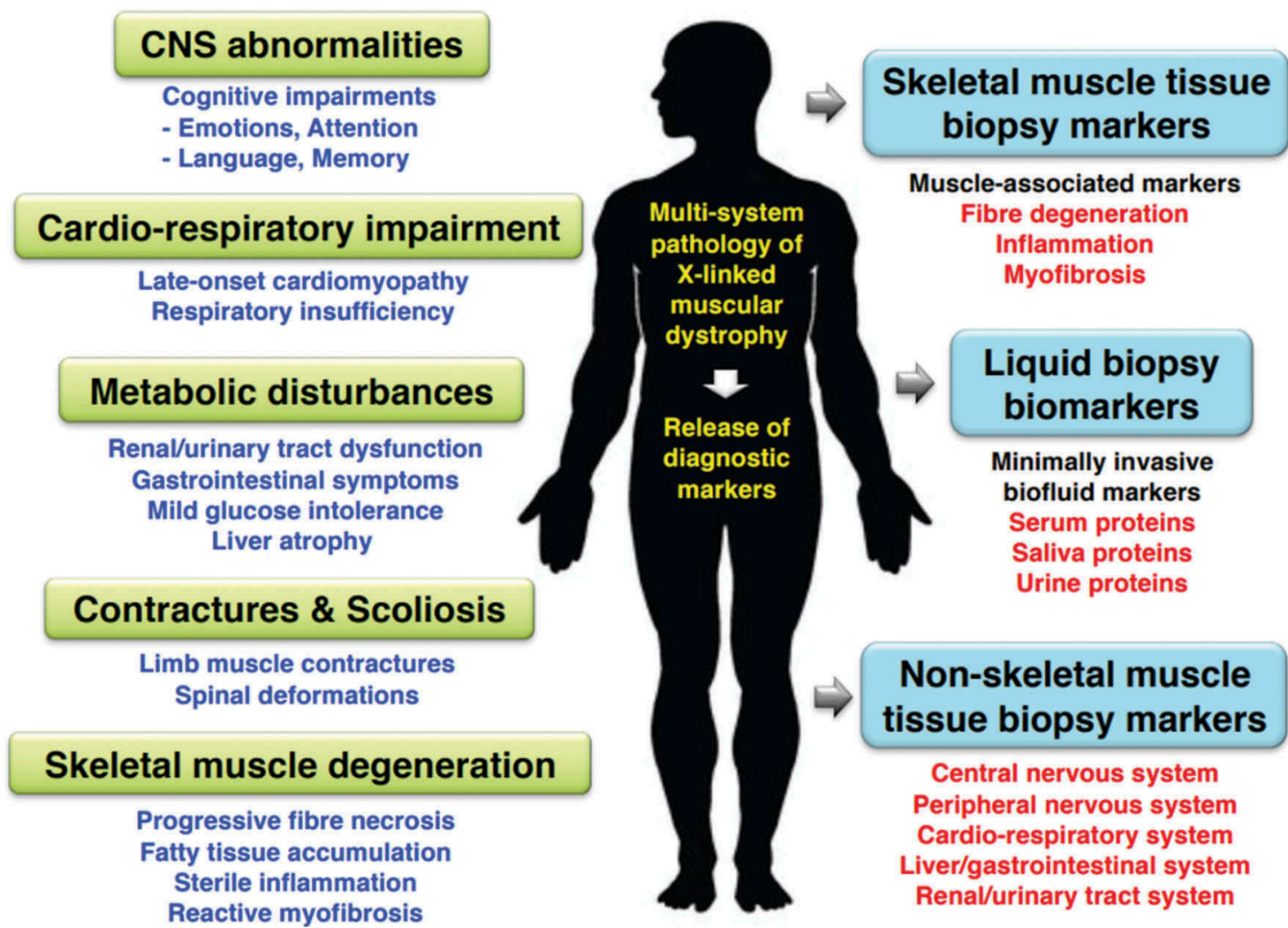

Figure 2. Overview of the multi-system disease process of Duchenne muscular dystrophy. Shown are the affected tissues, organs and biofluid systems, as well as the concept of tissue versus liquid biopsy biomarkers that may be useful for diagnostic, prognostic and therapy-monitoring purposes.

\section{Biomarker discovery for the molecular evaluation of muscular dystrophy}

Since only supportive treatments are available to address the devastating effects of progressive muscle degeneration and associated impairments of cardio-respiratory and cognitive functions in X-linked muscular dystrophy, there is an urgent need to improve diagnostic and prognostic methods to better evaluate novel therapeutic approaches to counter-act chronic muscle fibre wasting. Figure 2 summarizes the multi-system disease process of dystrophinopathy and the affected tissues, organs and biofluids, as well as the concept of tissue versus liquid biopsy markers that may be useful for diagnostic purposes. Dystrophic changes in the skeletal musculature are highly complex and include progressive fibre degeneration, reactive myofibrosis and sterile inflammation [16-18]. Cellular features of dystrophic muscles include increased fibre branching, more rounded cellular shapes, altered myofibre size, central nucleation due to degeneration-regeneration cycles, necrosis and fatty deposition.

Importantly, the immune response that usually supports repair mechanisms in acutely damaged skeletal muscle tissue was shown to be aberrant in the context of chronic muscle wasting. This involves both amplification of the innate immune system and activation of the acquired immune response, as extensively reviewed by Tidball et al. [18]. A perturbed crosstalk between the immune system and damaged muscles appear to amplify the dystrophic phenotype due to altered signalling patterns by immuno-modulators. Some of the most prevalent cell types of the innate immune response are present during the initial non-specific inflammatory response, including macrophages, neutrophil granulocytes and mast cells. However, more specific reactions also occur and are mediated by eosinophils, as well as key cells of the adaptive immune response such as cytotoxic CD8 + T-lymphocytes. This dysregulation of the immune response in association with chronic fibre injury is involved in promoting profibrotic changes that eventually cause severe myofibrosis [19]. Importantly, a longitudinal and multi-parametric analysis of fibrotic changes in dystrophic muscles highlighted the fact that endomysial fibrosis is the only significant myopathological characteristic that reliably correlates with the weakening of contractile strength [20]. Hence, the excessive accumulation of collagen and associated components of the extracellular matrix appears to be directly involved in the gradual decline in skeletal muscle elasticity and reduced motor functions in X-linked muscular dystrophy [21].

A major goal of current proteomic studies of muscular dystrophy is to identify novel protein biomarkers that are characteristic for individual aspects of the diverse pathobiochemical changes observed in dystrophinopathy. In general, biomarker types can be divided into (i) susceptibility markers that are 
useful to estimate the risk for disease initiation in otherwise healthy individuals, (ii) diagnostic markers for the initial differential and reliable detection of a specific disease process, (iii) prognostic markers that can be useful for envisaging disease progression and adverse clinical events, (iv) predictive markers that are capable for differential patient screening and their individual sensitivity towards therapeutic interventions, (v) pharmacodynamic markers that reflect the response of the body to a specific treatment, (vi) therapy-monitoring markers that are suitable for the repeated assessment of potential changes in pathological status due to therapy, and (vii) safetyrelated biomarkers that are capable of measuring cytotoxic side effects in association with aggressive treatments [12]. The availability of robust biomarker signatures is especially crucial for the evaluation of new experimental treatments.

Previous pharmacological trials have focused on modulating calcium homeostasis, cellular growth, energy metabolism, the immune response, inflammation, oxidative stress and blood flow. Currently the feasibility of various innovative therapeutic approaches is tested in preclinical or clinical trials. These new methodologies include stem cell therapy, myoblast transfer, utrophin substitution therapy, enhancement of the cellular stress response, transcutaneous electrical nerve stimulation and improved steroid therapy, as well as a variety of direct or indirect genetic approaches including plasmid transfer, viral transfer, naked DNA transfer, mini-dystrophin delivery, stop codon read-through therapy, exon-skipping therapy and CRISPR/Cas9-based partial genome editing [2224]. Potentially dangerous side effects due to de novo dystrophin expression following gene therapy were recently highlighted by the immunological evaluation of exon skipping in the $m d x$ mouse [25]. Newly synthesised dystrophin molecules were shown to trigger both cell-mediated and humoral immune responses, which suggests that exon skipping therapy might be complicated by a long-term autoimmune response and associated cellular damage [25].

In general, the detailed biomedical value and associated complications of these types of new therapies are not easily measured. Findings from clinical strength tests, which are partially based on psychological motivation, can be misleading. Routine testing of serum enzymes, such as creatine kinase or other general markers of muscle damage, are not specific enough for the reliable evaluation of a specific neuromuscular disorder, such as X-linked muscular dystrophy. To overcome this shortage of suitable disease markers, comparative proteomics suggests itself as an ideal screening tool for the highthroughput comparison of normal versus dystrophic samples. The flow diagram in Figure 3 outlines the general bioanalytical workflow used in the standardized mass spectrometry-based proteomic identification of novel biomarker candidates.
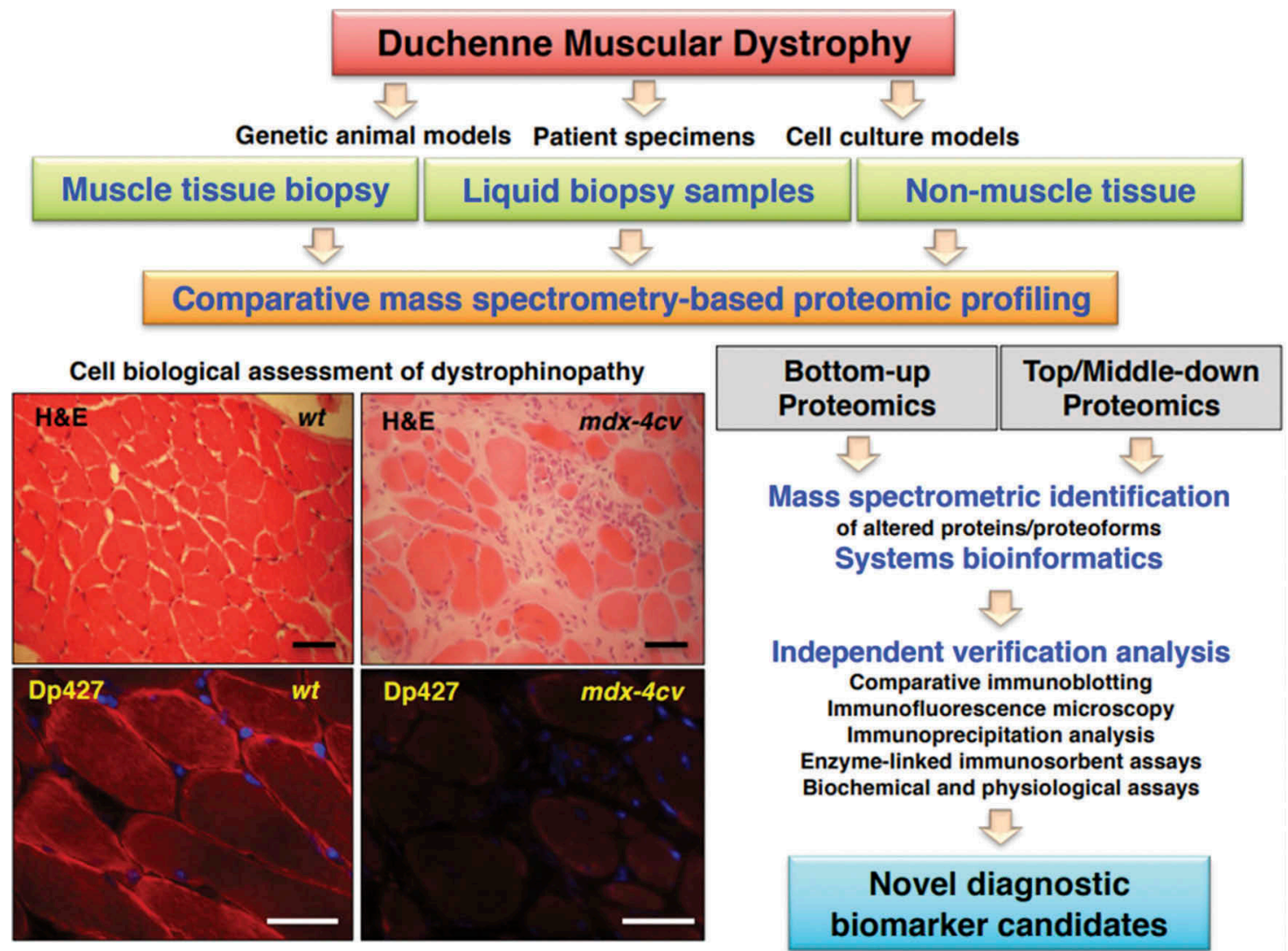

Independent verification analysis

Comparative immunoblotting

Immunofluorescence microscopy

Immunoprecipitation analysis

Enzyme-linked immunosorbent assays

Biochemical and physiological assays

\section{Novel diagnostic biomarker candidates}

Figure 3. Bioanalytical workflow of the mass spectrometry-based proteomic identification of novel biomarker candidates of X-linked muscular dystrophy. Shown is a diagram that summarizes the various bioanalytical steps that are used for the routine evaluation of protein markers. Transverse cryosections of diaphragm muscle from wild type $(w t)$ versus the dystrophic $m d x-4 c v$ mouse model of dystrophinopathy show typical histopathological features of dystrophin-deficient skeletal muscle fibres. Bar equals $50 \mu \mathrm{m}$. 
Patient specimens and cell culture models can be used to study both skeletal muscle and non-muscle tissues, as well as suitable biofluids. However, due to high levels of interindividual differences between patients and the extremely restricted amounts of human tissue biopsy specimens that are available for large-scale screening studies, most proteomic studies of muscular dystrophy have initially been carried out with samples from genetic animal models of this frequently inherited human neuromuscular disorder [26]. The histological and immunofluorescence microscopical analysis shown in Figure 3 illustrates the suitability of the dystrophic $m d x-4 c v$ strain, which arose from chemical mutagenesis [27], for proteomic analyses. Transverse cryosections of the diaphragm from this animal model show typical features of dystrophindeficient muscle fibres, such as differing fibre sizes, central nucleation, sterile inflammation and reactive myofibrosis.

For proteomic analyses of dystrophic tissues, proteins are routinely extracted from organs, tissues, cells, subcellular fractions, isolated protein assemblies or biological fluids and then separated by one-dimensional gel electrophoresis, twodimensional gel electrophoresis and/or liquid chromatography [13-15]. Typical bottom-up proteomics is based on the enzymatic digestion of protein mixtures followed by peptide mass spectrometry for the identification of individual protein species. In contrast, top-down or middle-down proteomics usually starts with isolated proteoforms that have been isolated to homogeneity by biochemical purification methods or highresolution two-dimensional gel electrophoresis. Intact proteins or large protein fragments are then treated in a similar way as in bottom-up approaches for the characterization of their peptide sequence and post-translational modifications. In comparative proteomics, systems bioinformatics plays a crucial role in the establishment of proteome-wide changes in particular protein families, biochemical pathways, cellular signalling cascades and protein interaction networks. The existence of large databanks of already catalogued and characterized skeletal muscle-associated proteins is extremely helpful for more refined proteomic investigations [28-31]. Routine cell biological, immunochemical and physiological assays are used for the independent verification of proteomic findings and the confirmation of new biomarker candidates. These tests often include combinations of comparative immunoblotting, enzyme-linked immunosorbent assays, immunofluorescence microscopy, immunoprecipitation, biochemical binding assays, physiological measurements and enzyme assays.

\section{Proteomic profiling of muscular dystrophy}

The proteomic analysis of cells, tissues and organs that are directly or secondarily involved in the multi-system pathology of dystrophinopathy has been carried out with a focus on the characterization of (i) full-length dystrophin Dp427-M and related isoforms, (ii) its tightly bound dystrophin-associated glycoprotein complex, (iii) the wider dystrophin complexome including components of the sarcolemma, intracellular cytoskeletal networks and the extracellular matrix, (iv) subtypes of dystrophic skeletal muscles with varying degrees of progressive degeneration, including predominantly slowtwitching versus faster twitching limb muscles, naturally protected extraocular muscles and highly fibrotic diaphragm muscle and (v) non-skeletal muscle tissues, such as the heart, brain and liver.

\subsection{Proteomic characterization of skeletal muscle dystrophin and the dystrophin-associated sarcolemmal protein complex}

The dystrophin-glycoprotein complex forms a transsarcolemmal bridge between the intracellular cytoskeletal network and the basal lamina component laminin and its associated extracellular matrix, which is crucial for lateral force transmission and stabilisation of the fibre periphery during repeated excitation-contraction-relaxation cycles [32]. In addition, the dystrophin complex functions as a molecular scaffold for anchoring signalling proteins and plasmalemmal receptors [33]. The proteomic profile of full-length dystrophin isoform Dp427-M and its tightly bound dystrophin-associated core complex, as well as the indirectly linked components that belong to the laminin-dystroglycan-actin axis are shown in Figure 4. Both, focused studies on the mass spectrometric identification and biochemical characterization of the dystrophin-glycoprotein complex, as well as systematic cataloguing studies of muscle tissue and cell lines, have been carried out over the last decade. A summary of major proteomic studies on dystrophin and the dystrophin complexome is provided in Table 1 [28-30,34-45].

Building on the initial biochemical characterization of the dystrophin complex by density gradient ultracentrifugation and chemical crosslinking analysis $[32,46,47]$, proteomic studies could confirm the close linkage of dystrophin with the integral glycoprotein $\beta$-dystroglycan and its associated extracellular laminin-binding protein a-dystroglycan [34,38-45]. Cortical actin, syntrophins, dystrobrevins, the $a, \beta, \gamma, \delta-$ sarcoglycan complex and laminin subunits are routinely identified by mass spectrometric surveys [28-30]. However, the integral protein sarcospan is often only identified by low sequence coverage using peptide mass spectrometry, even in highly enriched subcellular fractions from skeletal muscle [45], which is probably due to its low abundance and highly hydrophobic properties. Components of the wider dystrophin complex include caveolin, the desmoglein/desmoplakin complex, desmin, actinin, synemin, tubulins, vimentin and plectin on the intracellular side, and various collagen isoforms, fibronectin and biglycan on the extracellular side of muscle fibres [38-44] (Figure 4).

\subsection{Proteomic profiling of dystrophic skeletal muscles}

The pathobiochemical complexity of the dystrophic phenotype, which is characterized by progressive fibre degeneration, cycles of regeneration, fat substitution, reactive myofibrosis and inflammation in the skeletal musculature, complicates the interpretation of proteomic surveys. However, the usage of subcellular fractionation procedures, biochemical enrichment strategies, model systems from different animal species 


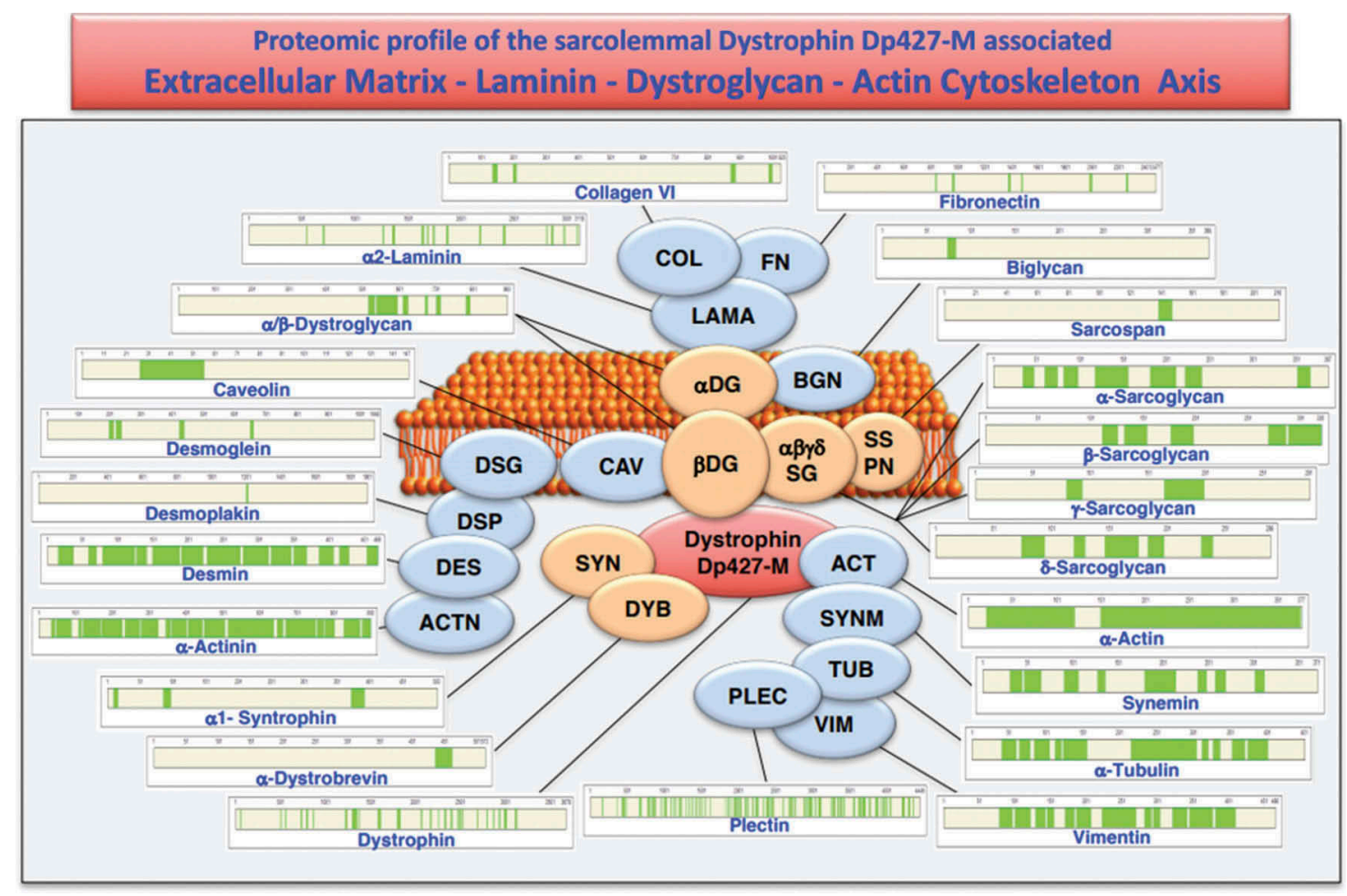

Figure 4. Proteomic profile of full-length dystrophin isoform Dp427-M and its tightly bound dystrophin core complex, as well as the indirectly associated components that belong to the laminin-dystroglycan-actin axis. The proteomic fingerprint of individual proteins is symbolized by green bars [45].

Table 1. Mass spectrometric identification of dystrophin and its tightly associated protein complex. Listed are major proteomic studies with a focus on the mass spectrometric characterization of dystrophin isoform Dp427-M and its closely associated sarcolemmal protein complex, as well as comprehensive cataloguing studies of skeletal muscles that have identified the various members of the dystrophin-glycoprotein complex. Abbreviations used: DIGE, difference in-gel electrophoresis; FASP, filter-aided sample preparation; IP, immunoprecipitation; LC-MS/MS, liquid chromatography tandem mass spectrometry; MALDI ToF, matrix assisted laser desorption/ionization time-of-flight; SDS-PAGE, sodium dodecyl sulfate polyacrylamide gel electrophoresis; WGA, wheat germ agglutinin; XL, chemical crosslinking.

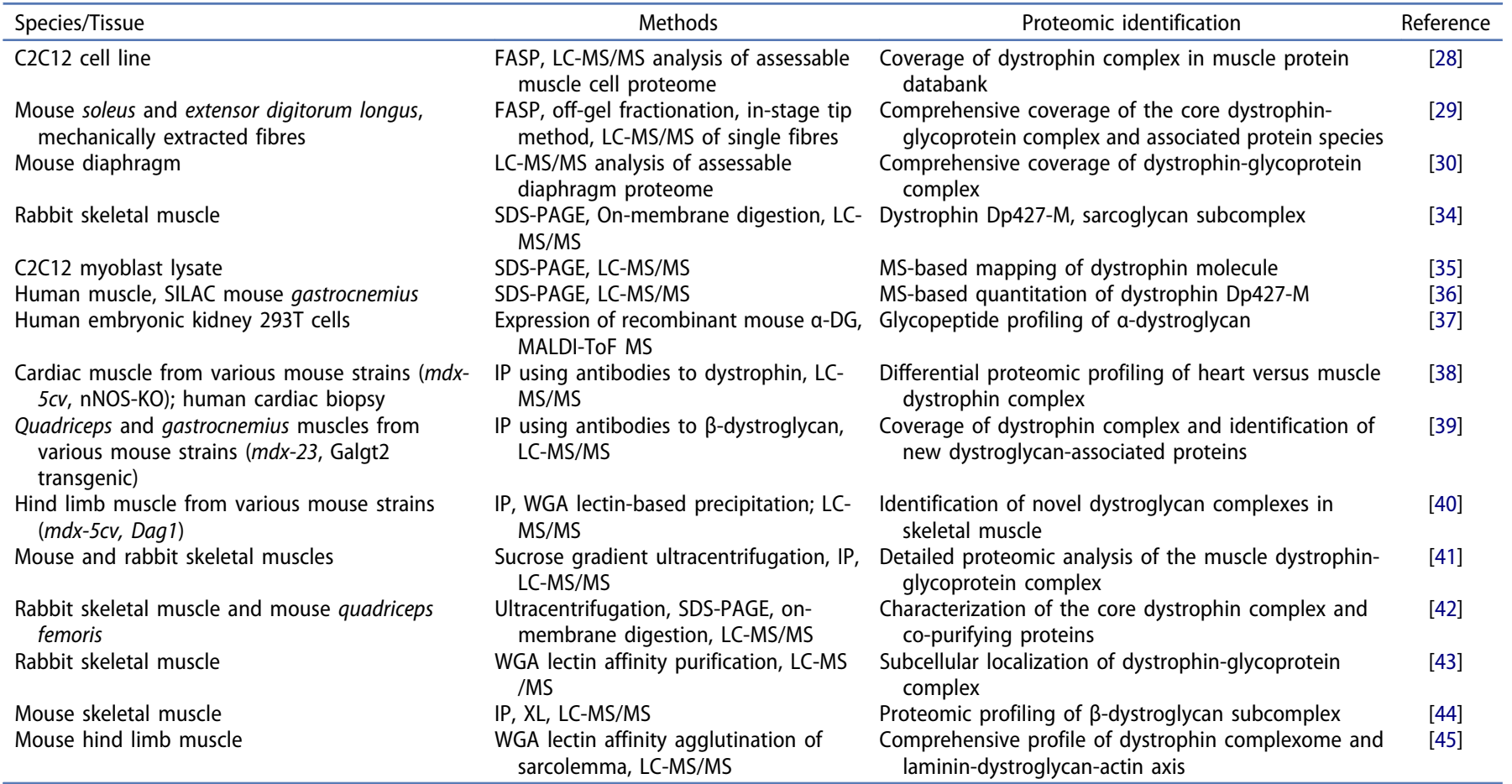


and the comparative analysis of different subtypes of skeletal muscles has helped in the establishment of differential effects of dystrophin deficiency on individual skeletal muscles. A listing of overlapping protein hits from individual proteomic studies has recently been provided in a supplementary file of a review on muscular dystrophy [15], but these tables have excluded crucial information from gel-based proteomics. Highresolution two-dimensional gel electrophoresis, especially in combination with differential fluorescent tagging of entire proteomes, is a highly effective way of analysing skeletal muscle tissue [31]. Thus, for an updated and inclusive presentation of promising proteomic markers, this article lists studies that were conducted with both gel-based and gel-free methodologies. This information could be extremely helpful for the future testing and clinical establishment of novel and more robust biomarkers of Duchenne muscular dystrophy.

Table 2 provides an overview of the diversity of protein changes that have been identified by the systematic comparison of various skeletal muscles using highly sensitive mass spectrometric techniques [30,39-42,44,45,48-78]. As recently reviewed [3], proteomic studies revealed that the dystrophindeficient skeletal musculature undergoes only moderate fibre type shifting on the level of bioenergetic pathways and the contractile apparatus. Although degenerative processes are observed in fast-twitching type llb fibres prior to slower twitching fibre populations, and a considerable number of fibres in Duchenne patients appear to contain mostly the adult slow MyHC isoform of myosin heavy chain, proteomic studies indicate only modest alterations in the overall sarcomeric apparatus $[14,15,17]$. Table 2 lists the subtypes of skeletal muscles investigated in individual proteomic studies, and therefore correlates types of muscle, such as fast versus slow and glycolytic versus oxidative fibre populations, with key proteome-wide changes. The table also lists the main techniques used during proteomic surveys of specific skeletal muscles and therefore puts the main proteomic findings reported in a specific publication in the context of muscle subtypes.

The proteomic identification of new protein candidates using gel-free versus gel-based approaches is usually confirmatory or at least complementary in nature. Two-dimensional gel electrophoresis has the advantage of separating specific proteoforms by their unique combination of isoelectric point and molecular mass $[48-55,57-59,61,63,65,70,78]$. This type of top-down proteomics visualizes the actual protein species prior to digestion and is thus especially useful for the comprehensive analysis of the various isoforms of the actin-myosin apparatus and metabolic proteins. In contrast, integral membrane proteins, very large protein species and molecules with extreme isoelectric points are often underrepresented in 2Dgel systems. These types of muscle proteins are more appropriately analyzed by one-dimensional gel electrophoretic techniques that can be combined with on-membrane digestion and mass spectrometry $[34,43,72,77]$ or affinity purification and immunoprecipitation approaches $[39,41,44,77]$. Alternatively, skeletal muscle proteins that are present in crude tissue extracts or subcellular fractions can be conveniently analyzed by bottom-up proteomics, which employs trypsination of total protein complements in combination with liquid chromatography and mass spectrometry $[30,45,56,60,62,64,66-69,71,73-76,78]$.

The majority of comparative proteomic analyses of dystrophic skeletal muscle tissues has shown a greater number of increased versus decreased protein species, which is probably due to the occurrence of degeneration/regeneration cycle in the absence of dystrophin. Overlapping proteomic hits suggest that a variety of skeletal muscle-associated proteins are suitable candidates for the establishment of a biomarker signature of X-linked muscular dystrophy. This includes marker proteins involved in fibre contraction, energy metabolism, cytoskeletal maintenance, the cellular stress response and ion homeostasis (Table 2). The initial gel-based proteomic screening of $m d x-23$ skeletal muscles identified a decreased concentration of adenylate kinase isoform AK1 [48], which was confirmed by several studies using both twodimensional gel electrophoresis and liquid chromatography $[50-52,56,59]$. Lower levels of adenylate kinase may be linked to abnormal nucleotide metabolism in muscular dystrophy [50]. Another striking characteristic of dystrophic fibres are decreased levels of the cytosolic $\mathrm{Ca}^{2+}$-binding protein regucalcin $[51,52]$ and the luminal $\mathrm{Ca}^{2+}$-sequestering proteins calsequestrin of the terminal cisternae region and sarcalumenin of the longitudinal tubules $[45,49,61,64]$. Changes in theses abundant $\mathrm{Ca}^{2+}$-binding proteins were identified in both the highly fibrotic diaphragm and less severely affected leg muscles, indicating a general role in the molecular pathogenesis of dystrophinopathy. The enhanced susceptibility of dystrophinlacking muscle fibres to micro-rupturing of the fragile sarcolemma causes an increased influx of $\mathrm{Ca}^{2+}$-ions, which in turn results in higher levels of proteolytic degradation [16]. The additional impairment of efficient $\mathrm{Ca}^{2+}$-buffering in the cytosol and lumen of the sarcoplasmic reticulum appears to exacerbate these physiological disturbances of excitation-contraction coupling in muscular dystrophy [49].

A very interesting biomarker candidate that has been repeatedly identified by mass spectrometry in dystrophindeficient contractile tissues is the CA3 isoform of carbonic anhydrase $[51,53,57,59,69-71]$. This metabolic enzyme catalyses the reversible hydration of carbon dioxide to carbonic acid. The CA3 isoform is present in all muscle fibre types with the highest density in slow-twitching type 1 fibres. Altered CA3 levels and its leakage into the circulatory system may be related to fibre type-specific susceptibilities and accompanying changes in the dystrophic phenotype [3]. Consistent changes were also reported for annexin isoforms ANX1, ANX2 and ANX5, which may be related to disturbed $\mathrm{Ca}^{2+}$-homeostasis and repair mechanisms within dystrophic fibres [42,45,50,61,64,67,71-74]. Potential compensatory mechanisms that are based on the up-regulation of cytoskeletal elements were confirmed by mass spectrometry. A drastically increased vimentin and desmin concentration seems to be a reliable indicator of cytoskeletal restructuring in Dp427-deficient fibres [51,52,54,55,57,58,63,66,67,77]. The fact that high levels of cellular stress is associated with muscular dystrophy was verified by the proteomic 
Table 2. Proteomic profiling of dystrophic skeletal muscle tissues. Listed are major proteomic studies with a focus on the comparative mass spectrometric analysis of dystrophin-deficient skeletal muscle tissues. Abbreviations used: 2D-GE, two-dimensional gel electrophoresis; DIGE, difference in-gel electrophoresis; ICAT, isotopecoded affinity tag; ICPL, isotope-coded protein labeling; IEF, isoelectric focusing; IP, immunoprecipitation; iTRAC, isobaric tag for relative and absolute quantitation; LC-MS/MS, liquid chromatography tandem mass spectrometry; MALDI ToF, matrix assisted laser desorption/ionization time-of-flight; MudPIT, multidimensional protein identification technology; SDS-PAGE, sodium dodecyl sulfate polyacrylamide gel electrophoresis; SILAM, stable isotope labeling in mammals; Stains-All, cationic carbocyanine dye staining; TMT, tandem mass tag; $\mathrm{XL}$, chemical crosslinking.

Species/Tissue
Mouse $m d x-23$ hind limb muscle
Mouse $m d x-23$ hind limb muscle
Mouse $m d x-23$ hind limb muscle (cytosol)
Mouse $m d x-23$ diaphragm
Mouse $m d x-23$ diaphragm
Mouse $m d x-23$ and antisense PMO-treated
diaphragm

Mouse $m d x-23$ extraocular muscle

Mouse $m d x-23$ gastrocnemius

Dog GRMD vastus lateralis

Mouse $m d x-23$ quadriceps and gastrocnemius

Mouse $m d x-23$ diaphragm

Mouse $m d x$ diaphragm

Mouse $m d x-23$ tibialis anterior

Dog GRMD cranial sartorius

Mouse $m d x-23$ diaphragm

Mouse $m d x-23$ gastrocnemius

Mouse $m d x-23$ soleus, extensor digitorum longus, flexor digitorum brevis and interosseus

Mouse $m d x-23$ diaphragm versus extraocular muscle TMT isobaric mass tagging, MudPIT, LC-MS/MS

Mouse $m d x-23$ hind limb muscles (microsomes)

Mouse $m d x-23$ diaphgram

2D-GE, LC-MS/MS

LC-MS/MS

Mouse $m d x-23$ diaphragm, soleus, extensor digitorum LC-MS/MS longus, flexor digitorum brevis and interosseus

Mouse $m d x-23$ and antisense PMO-treated tibialis anterior

Mouse $m d x-4 c v$ hind limb muscles (microsomes)

Mouse $m d x-23$ quadriceps following low-intensity endurance exercise

Mouse $m d x-4 c v$ hind limb muscles

iTRAC, IEF, LC-MS/MS

LC-MS/MS

2D-GE, MALDI-ToF MS

LC-MS/MS

Dog GRMD biceps femoris following allogenic MuStem cell application

Mouse $m d x-4 c v$ gastrocnemius and $\mathrm{C} 2 \mathrm{C} 12$ myoblasts LC-MS/MS

Pig DMD biceps femoris

LC-MS/MS

Mouse $m d x-23$ skeletal muscles

Mouse $m d x-23$ and $m d x-52$ gastrocnemius

Mouse $m d x-23$ quadriceps femoris

Mouse $m d x-4 c v$ skeletal muscles

Methods

Sucrose gradient ultracentrifugation, IP, LC-MS/MS SILAM mouse analysis, LC-MS/MS

Key proteomic changes

Decreased adenylate kinase AK1

Decreased calsequestrin CSQ1 and sarcalumenin

Increased creatine kinase, myosin light chain MLC2 and annexin ANX5; decreased adenylate kinase AK1

Increased heat shock protein cVHSP, desmin and vimentin; decreased adenylate kinase AK1, regucalcin, carbonic anhydrase CA3

Increased vimentin, desmin, albumin; decreased regucalcin, adenylate kinase $A K 1$, alphaB-crystallin

Reversal of expression changes in heat shock protein CvHSP, adenylate kinase AK1 and carbonic anhydrase CA3

Minimal changes; increased desmin

Increased vimentin,

various heat shock proteins

Increased phosphorylated tropomyosin-4; decrease in

PGC-1a regulated metabolic proteins

Increased levels of utrophin and ankyrin-1 in $m d x-23$ dystroglycan complexes

Increased desmin, vimentin; decreased adenylate kinase AK1 and carbonic anhydrase CA3

Increased collagen VI, dermatopontin, vimentin, alphaBcrystallin; decreased myozenin-1

Increased carbonic anhydrase CA3 during $m d x-23$ aging

Increased spectrin; decreased laminin-a2

Increased heat shock protein cvHSP, dermatopontin, decreased parvalbumin, calsequestrin CSQ1, adenylate kinase AK1, annexin ANX5

Complex changes in pathways related to kinases, cytoskeleton, energy metabolism and calcium homeostasis

Differential protein changes in individual muscles; increased alphaB-crystallin, vimentin, desmin; decreased parvalbumin

Differential expression levels; increased annexin ANX and ANX5, decreased calsequestrin CSQ1 in $m d x$ diaphragm

Increased heat shock protein Hsp70, transferrin, ferritin Increased periostin, dermatopontin, desmin, obscurin and vimentin

Increased annexin ANX2 and ANX5, lamin A/C-B and vimentin

Partial restoration of $m d x-23$ proteome following exon skipping, including dystrophin-associated proteins

Decrease in dystrophin complex, carbonic anhydrase CA3; increased anti-trypsin, myoferlin and periostin

Differential effect of exercise on carbonic anhydrase CA3 and superoxide dismutase SODC

Decrease in dystrophin complex, carbonic anhydrase CA3, parvalbumin; increased collagens, fibronectin, biglycan, dysferlin and annexins

MuStem cell-induced additional increase in annexin ANX1 and ANX5, ferritin, haptoglobin

Increased annexin ANX1 and ANX5, periostin, lumican, albumin

Increased caveolin; decreased fast troponin TnC, endoplasmin

Disruption of the dystrophin-glycoprotein complex in mutants

Increased dysferlin, annexin ANX1 and ANX2; alterations in mitochondrial proteins

Ultracentrifugation, SDS-PAGE, on- Decreased desmoglein and FABP1; increased annexin membrane digestion, LC-MS/MS ANX1, biglycan and fibronectin

Lectin agglutination of sarcolemma, Increased integrin and neural cell adhesion molecule NCAM1
Reference

$[48$

[50]

[59]

[60] 
Table 2. (Continued).

\begin{tabular}{|c|c|c|c|}
\hline Species/Tissue & Methods & Key proteomic changes & Reference \\
\hline Mouse $m d x-23$ skeletal muscles & $\mathrm{IP}, \mathrm{XL}, \mathrm{LC}-\mathrm{MS} / \mathrm{MS}$ & $\begin{array}{l}\text { Charcterization of } \beta \text {-dystroglycan and caveolin } \\
\text { subcomplexes in Dp427-deficient muscle }\end{array}$ & [44] \\
\hline Mouse $m d x-4 c v$ hind limb muscles (microsomes) & $\mathrm{XL}, \mathrm{SDS}-\mathrm{PAGE}, \mathrm{LC}-\mathrm{MS} / \mathrm{MS}$ & $\begin{array}{l}\text { Increased oligomerization of myoferlin, caveolin, } \\
\text { vimentin and tubulin }\end{array}$ & [77] \\
\hline $\begin{array}{l}\text { Mouse } m d x-4 c v \text { hind limb muscles following } \\
\text { treadmill exercise }\end{array}$ & 2D-GE, MALDI-ToF MS & $\begin{array}{l}\text { Exercise-induced increase in fast troponin TnT and Tnl, } \\
\text { myozenin, glycolytic enzymes }\end{array}$ & [78] \\
\hline Mouse $m d x-4 c v$ skeletal muscles & $\begin{array}{l}\text { Lectin affinity agglutination of } \\
\text { sarcolemma, LC-MS/MS }\end{array}$ & $\begin{array}{l}\text { Increased myoferlin, dysferlin and annexins; decreased } \\
\text { periaxin and myelin PO }\end{array}$ & {$[45]$} \\
\hline Mouse $m d x-4 c v$ diaphragm & LC-MS/MS & $\begin{array}{l}\text { Increased myosin- } 8 \text { and vitronectin; decreased } \\
\text { parvalbumin and fatty acid binding protein FABP3 }\end{array}$ & {$[30]$} \\
\hline
\end{tabular}

identification of a variety of molecular chaperones, including the heat shock proteins cvHsp, aB-crystallin, Hsp70 and Hsp90 [51,52,55,58,61,63,65].

Reactive myofibrosis is a histopathological hallmark of X-linked muscular dystrophy and closely related to loss in motor functions [17,19-21]. Proteomics established an increased density of a variety of markers of the extracellular matrix, such as collagens, dermatopontin, the matricellular protein periostin, fibronectin, biglycan, lumican and asporin $[42,58,61,66,69,71,73]$. Additional biomarker candidates of dystrophinopathy are represented by albumin, myosin light chains, the actin binding-protein profilin, the lipid dropletassociated protein perilipin and various glycolytic and mitochondrial enzymes [30,39-42,44,45,48-78]. Figure 5 gives an overview of the wider dystrophin complexome of the muscle fibre periphery and its association with the extracellular matrix, the cytoskeletal network and the muscle membrane system consisting of the sarcolemma, transverse tubules and the sarcoplasmic reticulum, as revealed by proteomic studies [39-45]. The concentration of a large number of these directly or indirectly dystrophin-associated proteins is changed in dystrophic skeletal muscles and these pathobiochemical alterations can now be used as proteome-wide evidence for establishing a robust biomarker signature of dystrophinopathy (Table 2).

\subsection{Proteomic analysis of non-skeletal muscle tissues}

Although dystrophinopathies are primarily classified as muscle diseases with characteristic neuromuscular symptoms [5], Duchenne muscular dystrophy is a multi-system disorder with severe complications due to cardiac failure, respiratory dysfunction, scoliosis, impaired liver metabolism, renal abnormalities and cognitive impairments [9]. Most studies into proteome-wide changes in non-skeletal muscle tissues [79-86] have focused on preparations from the dystrophin-deficient heart [38,79-81,84], but muscular dystrophy-related effects on the brain [82,86], kidney [83] and liver [85] have also been studied by proteomics. Investigations using both gel-based and gel-free systems have established changed concentration levels in protein markers of energy metabolism, ion homeostasis, the extracellular matrix and cytoskeletal networks. Table 3 lists proteomic biomarker candidates from non-skeletal muscle tissues that are significantly changed in X-linked muscular dystrophy [79-86]. This includes cardiac-specific changes in the core dystrophin complex, mitochondrial enzymes, the basal lamina and associated extracellular matrix [38,79$81,84]$, which might be linked to the cardio-respiratory syndrome in X-linked muscular dystrophy [5].

An interesting finding in relation to hepatic alterations is the identification of elevated levels of fatty acid binding protein FABP5 in the $m d x-4 c v$ liver. Dystrophinopathies appear to be associated with secondary alterations that especially affect fatty acid transportation in liver tissue [85]. A useful indicator of potential side effects of exon skipping therapy on the kidney was identified as the renal marker protein meprin MEP-1 [83]. Since a subset of children suffering from $X$-linked muscular dystrophy is also affected by neuropathological complications that affect emotion, language, attention and memory [5], it is of interest that the proteomic analysis of the central nervous system from the $m d x-4 c v$ mouse model has established an increased concentration of glial fibrillary acid protein GFAP $[82,86]$. Since GFAP is an intermediate filament component of astrocytes in the brain, its elevated concentration implies neurodegeneration-associated astrogliosis in muscular dystrophy. Thus, gliosis may be a contributing factor that is involved in dystrophinopathy-related cognitive impairments and brain abnormalities.

\section{Targeted biomarker discovery in biofluids}

In paediatric muscle disease diagnostics, the routine usage of minimally- or non-invasive methods is usually advantageous over potentially more uncomfortable muscle biopsy techniques [87]. Importantly, in genetic disorders of early childhood, swift and robust diagnostic and prognostic procedures will be crucial for the reliable evaluation of new therapeutic strategies, such as gene or stem cell therapy. Thus, biofluid-associated biomarkers are excellent candidates for the implementation of liquid biopsy procedures in the field of muscular dystrophy.

\subsection{Advances in biofluid array technology}

Antibody arrays (or forward-phase protein assays; FPPAs) are mainly applied to quantify analytes that are present in complex samples. Antibody arrays are an established proteomic technology providing an exceptional methodology for various 


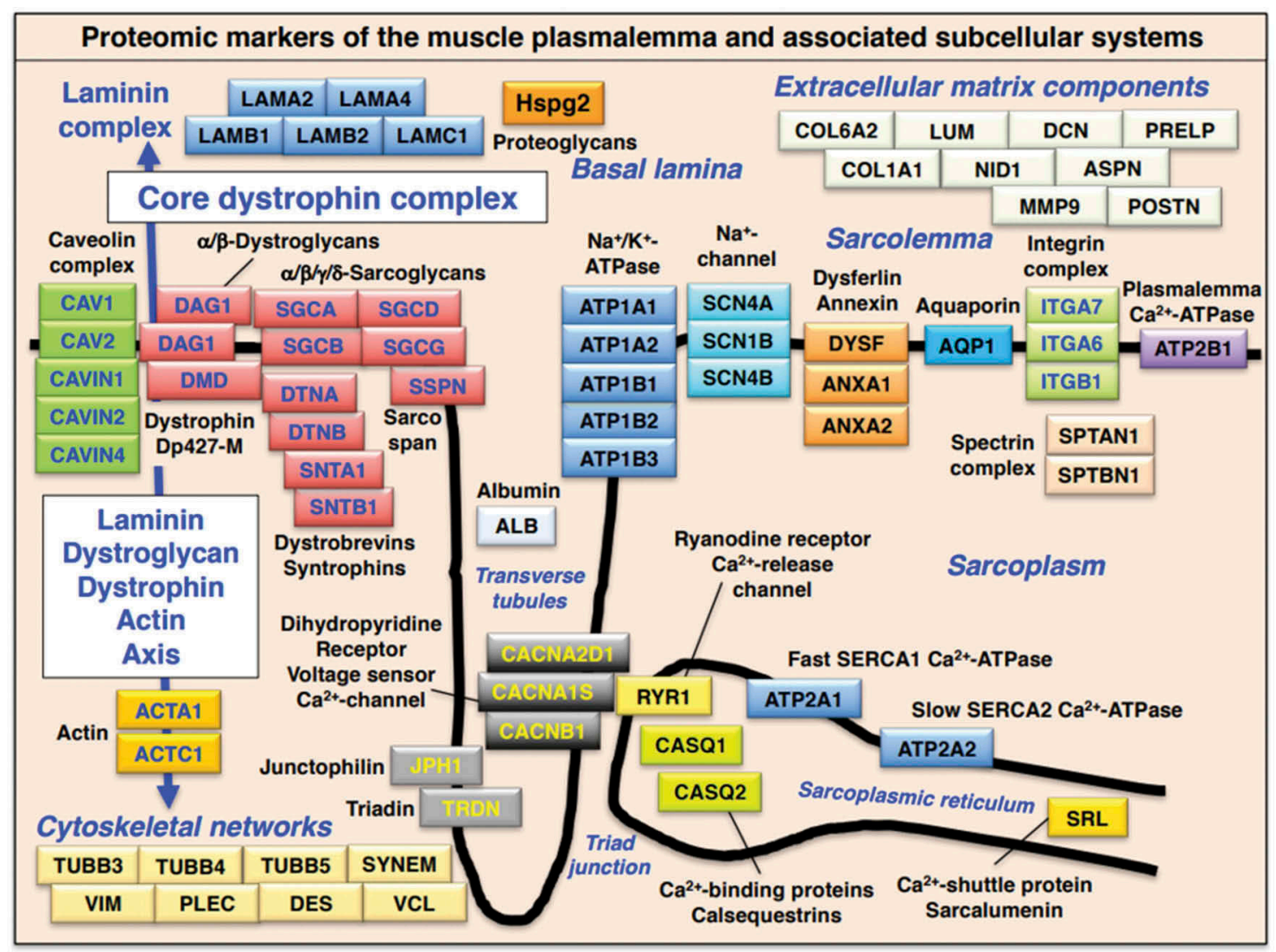

Figure 5. Overview of the wider dystrophin complexome and sarcolemmal protein markers as revealed by mass spectrometry-based proteomics. Shown are the various protein species that were shown to be linked to the wider sarcolemmal protein network and its associated subcellular systems, including the extracellular matrix, the cytoskeletal network, the plasmalemma, the transverse tubules and the sarcoplasmic reticulum.

applications, such as protein expression profiling and biomarker discovery (diagnostics/prognostics/therapy selection/disease monitoring) in samples ranging from cells, tissues, serum and conditioned media to more novel biofluids such as nipple aspirate fluid and tears [88]. An antibody array is a multiplex immunoassay that can utilise the ELISA (enzymelinked immunosorbent assay) sandwich antibody pair principle, which allows researchers to detect potentially several hundred proteins within a single analysis. The antibodies are individually deposited in an ordered pattern, with each antibody printed as replicates to improve confidence in subsequent results. Positive and negative controls are included to maximize data reliability. Bead-based arrays of the Luminex type rely on colour-coded beads, pre-coated with analytespecific capture antibody for the molecule of interest, with each antigen then being identified based on bead colour [89].

The typical workflow of an antibody microarray involves the choice of an appropriate antibody array platform (solid or bead), blocking of non-specific reactive groups, selection of suitable samples containing soluble proteins of interest and incubation with the antibody array, where targeted proteins from the sample are captured by the antibodies. The resulting binding events are reported precisely by fluorescent labelling of the sample or by the addition of a secondary detection reagent. Most of the antibody arrays can achieve $\mathrm{pg} / \mathrm{ml}$ detection for specific antigens, similar to single ELISA detection methodology [90]. However, to overcome potential crossreactivity and target protein abundance issues and concerns at detecting low/high abundant target proteins on the same array, more specialised arrays can be developed to mitigate for these trepidations. Current off-the-shelf antibody array panels include those specifically developed to detect and quantitate various cytokines, chemokines, adipokines, growth factors, proteases, soluble receptors and adhesion molecules. The custom option offers researchers the flexibility to design tailored panels to meet niche demands where novel biomarkers or marker molecules harbouring specific post-translation modifications need to be included as part of an antibody array panel.

Antibody array technology has proven to be a successful approach for identifying urgently needed biomarkers for muscular dystrophies. Using an antibody bead array platform with 384 antibodies, eleven proteins associated with muscular dystrophy were identified from the analysis of both serum and plasma patient samples [91]. Four proteins were established as having increased abundance levels in blood from Duchenne and Becker's muscular dystrophy patients compared to control groups, i.e. carbonic anhydrase CA3, myosin light chain MYL3, mitochondrial malate dehydrogenase $\mathrm{MDH} 2$ and electron transfer flavoprotein ETFA. If confirmed by longitudinal studies, these new protein signatures could then be used to 
Table 3. Proteomic profiling of non-skeletal muscle tissues in association with X-linked muscular dystrophy. Listed are major proteomic studies with a focus on the comparative mass spectrometric analysis of non-skeletal muscle tissues, including heart, liver, kidney and brain specimens. Abbreviations used: LC-MS/MS, liquid chromatography tandem mass spectrometry; DIGE, difference in-gel electrophoresis; IP, immunoprecipitation; SILAM, stable isotope labeling in mammals.

\begin{tabular}{|c|c|c|c|}
\hline Species/Tissue & Methods & Key proteomic changes & Reference \\
\hline Mouse $m d x-23$ heart & 2D-DIGE, LC-MS/MS & Differential changes in mitochondrial and metabolic proteins & [79] \\
\hline Mouse $m d x-23$ heart & 2D-DIGE, LC-MS/MS & $\begin{array}{l}\text { Increased lamin-A/C; decreased ATP synthase, fatty acid binding protein } \\
\text { FABP3 and adenylate kinase AK1 }\end{array}$ & [80] \\
\hline Mouse $m d x-5 c v$ heart & $\begin{array}{l}\text { IP using antibodies to } \\
\text { dystrophin, LC-MS/MS }\end{array}$ & Altered cardiac dystrophin interactions with syntrophin/dystrobrevin & [38] \\
\hline Mouse $m d x-23$ heart & LC-MS/MS & Cardiac-specific decrease in laminin, nidogen and annexin ANX6 & [81] \\
\hline Mouse $m d x-4 c v$ brain & LC-MS/MS & Increased glial fibrillary acidic protein, calretinin, annexin ANX5 and vimentin & [82] \\
\hline $\begin{array}{l}\text { Mouse } m d x-23 \text { kidney following } \\
\text { antisense PMO treatment }\end{array}$ & SILAM mouse analysis & $\begin{array}{l}\text { PMO-related increase in glutamyl aminopeptidase and kidney marker meprin } \\
\text { MEP-1 }\end{array}$ & [83] \\
\hline Mouse $m d x-4 c v$ heart & LC-MS/MS & $\begin{array}{l}\text { Increased periostin, asporin, lumican, cardiac-specific myosin light chain } \\
\text { kinase; decreased laminin and sarcalumenin }\end{array}$ & [84] \\
\hline Mouse $m d x-4 c v$ liver & LC-MS/MS & $\begin{array}{l}\text { Increased fatty acid binding protein FABP5, ferritin and calumenin; decreased } \\
\text { phospho-glycerate kinase and perilipin }\end{array}$ & [85] \\
\hline Mouse $m d x-4 c v$ brain & LC-MS/MS & Secondary disturbances in fatty acid and carbohydrate metabolism & [86] \\
\hline
\end{tabular}

monitor disease progression and facilitate clinical management decisions for dystrophic patients. Ho and co-workers [92] demonstrated how a Luminex mouse 38-plex kit was used to determine if $m d x / m T R G 2$ mice may have developed a peripheral inflammatory cytokine signature following systemic delivery of micro-dystrophin vectors, an investigational therapy involving systemic gene replacement to introduce a functional dystrophin gene to skeletal and cardiac muscles. Proteomic findings indicated an overall decrease in abundance levels of IFN- $\gamma$, TNF- $a$, IL-6, and IL-17A within the vectortreated group as compared with the vehicle group, however these results were not statistically significant.

Lysate arrays (or reverse phase protein arrays; RPPAs) represent an innovative technology that combines high throughput analysis with minimal sample consumption [93]. Small amounts (low ng range) of protein (lysates from cells/tissue) are printed onto nitrocellulose or glass slides. Proteins of interest are then quantified using highly specific primary antibodies, with slides potentially containing hundreds of individual samples, with a specific pattern for each sample containing serial dilutions and replicates. Escher et al. [94] demonstrated how powerful RPPA approaches are when evaluating changes in protein expression between healthy and diseased muscle tissue, as well as cultured primary myotubes. This study established that the differential diagnosis of muscular dystrophies using RPPAs in combination with a set of diagnostic antibodies is a worthwhile strategy, as exemplified by increased sarcoglycan signals in limb-girdle muscular dystrophy of type LGMD2A as compared to controls.

\subsection{Novel biofluid markers of dystrophinopathy}

Several proteomic studies have characterized blood, urine and saliva samples for the establishment of novel biofluid-based biomarkers of dystrophinopathy. Many complex biological fluids are readily available and can be easily collected for systematic proteomic analysis [87]. If specific proteoforms are passively released or actively secreted in response to pathophysiological processes, these types of proteins are an excellent starting point for designing new diagnostic assays, establish superior prognostic tests and develop more reliable techniques for the continued monitoring of novel therapeutic approaches to treat X-linked muscular dystrophy. Table 4 lists biomarker candidates that have been identified through the systematic screening of suitable biofluids [91,95-113]. Importantly, glucocorticoids are routinely used for treating chronic inflammatory conditions, including dystrophinopathies, making biofluid proteomics an essential part of the establishment of biomarkers of the anti-inflammatory response to this category of drugs [114]. Systematic investigations with a focus on serum biomarkers for chronic corticosteroid treatment revealed new candidate pharmacodynamic markers for evaluating anti-inflammatory drug efficacy, including leptin and matrix metalloproteinase MMP3 [115].

Proteomic screening studies have used samples from established animal models of muscular dystrophy, as well as blood and urine specimens from Duchenne patients. The identification of proteomic biomarker candidates in the blood included the confirmation of general indicators of muscle damage, such as creatine kinase, myoglobin and glycolytic enzymes, as well as novel proteins involved in metabolism, the extracellular matrix and the sarcomeric structures $[91,95-98,100-110]$. Significant changes included fibronectin, fibrinogen, carbonic anhydrase CA3, myosin light chain MLC3, mitochondrial malate dehydrogenase, titin, myomesin, troponin Tnl, calcium/calmodulin-dependent protein kinases, fatty acid binding proteins and the inflammationinduced plasma protein haptoglobin. In addition, leptin was identified as a new biomarker candidate and is potentially linked to the metabolic syndrome in Duchenne patients $[116,117]$.

Interestingly, urine samples from Duchenne patients contained increased levels of uromodulin, which is exclusively synthesised in renal tissue and presents the most abundant kidney protein in urine, and $\mathrm{N}$ - and $\mathrm{C}$-terminal fragments of the giant muscle protein titin [99]. Titin is a stabilising half-sarcomere spanning component of the acto-myosin apparatus in skeletal muscle fibres [7] and the appearance of titin fragments in urine indicates the pathological release of this structural protein into the circulatory system due to muscular dystrophy. The recent mass spectrometric survey of whole saliva from the $m d x-4 c v$ 
Table 4. Proteomics of biofluid changes in association with X-linked muscular dystrophy. Listed are major proteomic studies with a focus on the comparative mass spectrometric analysis of biofluids, including serum, urine and saliva. Abbreviations used: 2D-GE, two-dimensional gel electrophoresis; LC-MS/MS, liquid chromatography tandem mass spectrometry; DMD, Duchenne muscular dystrophy; ELISA, enzyme-linked immunosorbent assay; MALDI ToF, matrix assisted laser desorption/ionization time-of-flight; SILAC, stable isotope-labeled amino acids.

\begin{tabular}{|c|c|c|c|}
\hline Species/Tissue & Methods & Key proteomic changes & Reference \\
\hline $\begin{array}{l}\text { Mouse } m d x-23 \text { and } m d x-3 c v \\
\text { serum }\end{array}$ & $\begin{array}{l}\text { Magnetic beads affinity } \\
\text { purification, MALDI-ToF MS }\end{array}$ & Identification of differentiating N-terminal peptide of coagulation factor XIIIa & [95] \\
\hline Mouse $m d x-23$ plasma & 2D-GE, LC-MS/MS & $\begin{array}{l}\text { Increased fibrinogen, epidermal growth factor } 2 \text { receptor and glutathione peroxidase } \\
\text { GPX3 }\end{array}$ & [96] \\
\hline $\begin{array}{l}\text { Secretome of mouse } m d x-23 \\
\text { myotubes }\end{array}$ & SILAC labelling, LC-MS/MS & $\begin{array}{l}\text { Enrichment of LAMP1/MLC-1 (lysosomal-associated membrane protein/myosin light } \\
\text { chain) - positive vesicles }\end{array}$ & [97] \\
\hline Human DMD serum & $\begin{array}{l}\text { ProteoMiner beads enrichment, } \\
\text { LC-MS/MS, ELISA }\end{array}$ & Increased fibronectin levels & [98] \\
\hline $\begin{array}{l}\text { Human DMD serum and } \\
\text { plasma }\end{array}$ & $\begin{array}{l}\text { Large-scale screening with } \\
\text { antibody bead array platform }\end{array}$ & $\begin{array}{l}\text { Increased carbonic anhydrase CA3, myosin light chain MLC3, mitochondrial malate } \\
\text { dehydrogenase } \mathrm{MDH} 2 \text {, electron transfer flavoprotein ETFA }\end{array}$ & [91] \\
\hline $\begin{array}{l}\text { Human DMD and mouse } \\
m d x-23 \text { urine }\end{array}$ & $\begin{array}{l}\text { Sample concentration, LC-MS } \\
\text { /MS }\end{array}$ & Increased uromodulin and N-/C-terminal titin fragments, decreased cubulin & [99] \\
\hline $\begin{array}{l}\text { Mouse } m d x-23 \text { and } m d x-52 \\
\text { and human DMD serum }\end{array}$ & $\begin{array}{l}\text { SILAC mouse analysis, LC-MS } \\
\text { /MS }\end{array}$ & Increased titin, myosin light chain MLC1/3, myomesin MYOM3, filamin-C, myoglobin & [100] \\
\hline Mouse $m d x-23$ urine & $\begin{array}{l}\text { SILAM mouse technology, } \\
\text { antisense PMO treatment }\end{array}$ & Increase in clusterin, differential changes in gamma-glutamyltranspeptidase GGT1 & [83] \\
\hline $\begin{array}{l}\text { Human DMD and mouse } \\
m d x-23 \text { serum }\end{array}$ & $\begin{array}{l}\text { Immuno-depletion, LC-MS/MS, } \\
\text { antisense PMO treatment }\end{array}$ & Increased myomesin MYOM3, pyruvate kinase, carbonic anhydrase CA3 & [101] \\
\hline $\begin{array}{l}\text { Human } \mathrm{DMD} \text { and mouse } \\
\quad m d x-23 \text { serum }\end{array}$ & $\begin{array}{l}\text { Aptamer-based SOMAscan } \\
\text { screening }\end{array}$ & $\begin{array}{l}\text { Identification of troponin Tnl, phosphglycerate mutase PGAM1, calcium/calmodulin- } \\
\text { dependent protein kinase CAMK2b and Cytochrome-c }\end{array}$ & [102] \\
\hline Human DMD serum & $\begin{array}{l}\text { Aptamer-based SOMAscan } \\
\text { screening }\end{array}$ & $\begin{array}{l}\text { Identification of troponin Tnl, carbonic anhydrase CA3, myoglobin, fatty acid binding } \\
\text { protein FABP3 }\end{array}$ & [103] \\
\hline Human DMD serum & 2D-HPLC, MALDI-ToF MS & Identification of titin, calmodulin-like protein CALM-5 and carbonic anhydrase CA1 & [104] \\
\hline Human DMD serum & SOMAscan screening, LC-MS/MS & Overview of DMD serum biomarker candidates & [105] \\
\hline Mouse $m d x-4 c v$ serum & Immuno-depletion, LC-MS/MS & Increased levels of inflammation-induced plasma marker haptoglobin & [106] \\
\hline $\begin{array}{l}\text { Mouse } m d x-23 \text { and } \\
\text { transgenic } m d x-23 \text { Fiona } \\
\text { serum }\end{array}$ & $\begin{array}{l}\text { Aptamer-based SOMAscan } \\
\text { screening }\end{array}$ & $\begin{array}{l}\text { Increased utrophin related identification of tumor necrosis factor receptor GITR, } \\
\text { myosin-binding protein } C \text { and heat shock protein Hsp60 }\end{array}$ & [107] \\
\hline $\begin{array}{l}\text { Human DMD and mouse } \\
m d x-23 \text { serum }\end{array}$ & $\begin{array}{l}\text { Immuno affinity purification, LC- } \\
\text { MS/MS }\end{array}$ & Decreased myostatin in DMD and other neuromuscular disorders & [108] \\
\hline Human DMD serum & $\begin{array}{l}\text { Aptamer-based SOMAscan } \\
\text { screening }\end{array}$ & $\begin{array}{l}\text { Identification of troponin Tnl, carbonic anhydrase CA3, myoglobin and fatty acid } \\
\text { binding protein FABP3 }\end{array}$ & [109] \\
\hline $\begin{array}{l}\text { Mouse } m d x-4 c v \text { saliva and } \\
\text { serum }\end{array}$ & Immuno-depletion, LC-MS/MS & Identification of differential saliva/serum markers & [110] \\
\hline Human DMD serum & $\begin{array}{l}\text { Aptamer-based SOMAscan } \\
\text { screening }\end{array}$ & $\begin{array}{l}\text { Identification of calcium/calmodulin-dependent protein kinases CAMK2a and } \\
\text { CAMK2b, carbonic anhydrase CA3 and fatty acid binding protein FABP3 }\end{array}$ & [111] \\
\hline Mouse $d K O-H o m$ serum & LC-MS/MS & $\begin{array}{l}\text { Dystrophin/utrophin double-KO related decrease in haptoglopin and increase in } \\
\text { peroxiredoxin-2 }\end{array}$ & [112] \\
\hline Mouse $m d x-4 c v$ saliva & LC-MS/MS & Increased kallikrein Klk-1 and Klk1-related peptidases b1, b5 and b22 & [113] \\
\hline
\end{tabular}

model of dystrophinopathy identified an increased concentration of kallikrein-1 and its related peptidases Klk1-b1, Klk1-b5 and Klk-b22 [113]. Significantly higher levels of kallikrein-1 were also found in $m d x-4 c v$ serum samples [110]. These altered concentrations of kallikreins in biofluids are probably related to muscular dystrophy-related changes in cellular signalling mechanisms, remodelling of the extracellular matrix and a modified immune response. The successful proteomic screening of plasma, serum, urine and saliva samples demonstrates the suitability of liquid biopsy methods for the evaluation of body-wide changes in dystrophinopathy.

Figure 6 provides an overview of proteomic biomarker candidates that are associated with X-linked muscular dystrophy. The diagram lists (i) primary tissue markers of the disintegration of the core dystrophin complex, (ii) protein families that are secondarily affected in muscular dystrophy and (iii) biofluid markers that are found in the circulatory system due to passive protein leakage or active protein release.

\section{Expert opinion}

Since many chronic disorders, such as diabetes, neurological diseases, cardiovascular disorders or cancer trigger a variety of relatively general pathophysiological alterations in the composition of the circulatory system, it is crucial to establish a skeletal muscle disease-specific damage marker signature. Often changes in the levels of hormones, cytokines, metabolic enzymes or signalling proteins are not specific enough to properly evaluate a specific neuromuscular pathology. However, based on the systematic application of mass spectrometry-based proteomics in the field of muscular dystrophy research, select dystrophin-associated proteins, a large number of indirectly affected tissue components and a considerable array of biofluid-associated proteins can now be used to develop novel and hopefully more reliable diagnostic and prognostic marker assays. It should also be possible to exploit some newly established proteomic markers as therapeutic targets to treat progressive fibre wasting in X-linked muscular dystrophy. 


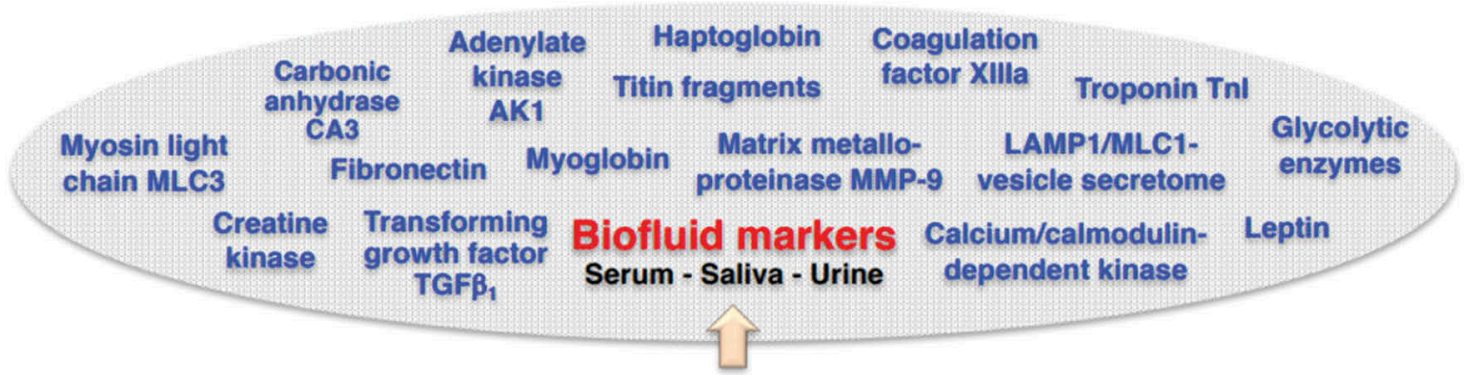

Passive protein leakage or active protein release into circulatory system

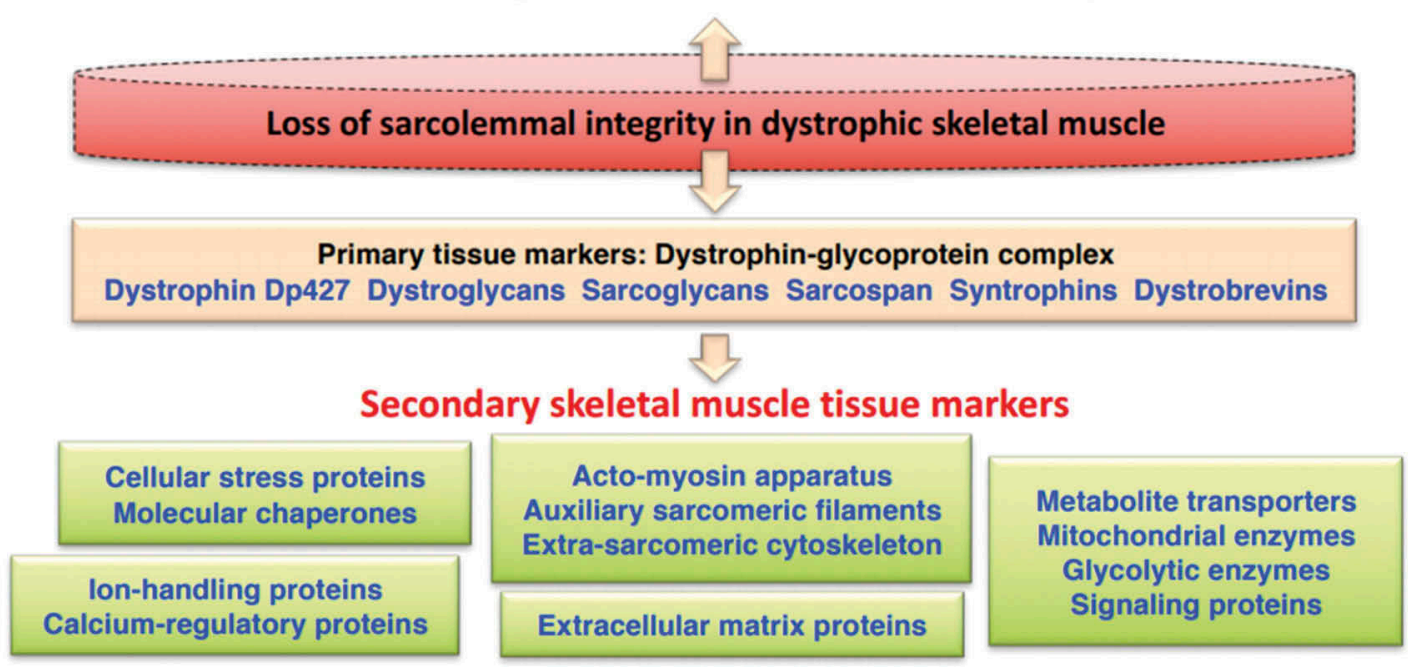

Figure 6. Schematic presentation of proteomic biomarker candidates that are associated with dystrophinopathy. The diagram lists primary tissue-associated markers of the sarcolemmal dystrophin-glycoprotein complex, protein families that are secondarily affected during chronic fibre wasting and biofluid markers that are passively leaked or actively released from dystrophic muscle tissue.

Especially liquid biopsy procedures that use independently verified protein biomarkers should be helpful to improve the diagnosis and therapy monitoring of X-linked muscular dystrophy. The recent identification of additional muscular dystrophyspecific enzymes in easily sourced biofluids, such as blood, urine and saliva, will be extremely useful for clinical applications that are based on the dependable measurement and analysis of disease progression and therapeutic response. Serumassociated fibronectin, carbonic anhydrase, myosin light chain, myomesin, troponin, fatty acid binding proteins and haptoglobin, as well as titin fragments in urine and saliva kallikrein have great potential to be useful biomarkers of dystrophinopathy. In contrast to the high costs, invasive character and clinical necessity of full asepsis of muscle biopsy procedures, non-invasive liquid biopsy procedures have the advantage of being more cost-effective, quicker and can be applied in a repeated manner for optimum therapy monitoring.

Over the next few years, it will be critical to verify the general biomedical suitability of the newly identified proteomic marker molecules that are associated with X-linked muscular dystrophy. In contrast to biofluid analyses from patients, the proteomic identification of tissue-associated marker molecules has almost exclusively been carried out with animal models of X-linked muscular dystrophy. Hence, there is an urgent need to extent proteomic studies of dystrophic skeletal muscle fibres to human tissue samples. For the translation of biomarker usage as a routine diagnostic tool in the clinical setting, potential problems with inter-individual differences in large patient cohorts have to be evaluated. Although it is difficult to obtain large numbers and quantities of muscle biopsy material from paediatric patients, it should be possible to perform comparative profiling studies with restricted amounts of human tissue by using advanced and highly sensitive mass spectrometric approaches. Both, miniaturized gel- and/or liquid chromatography-based procedures should be suitable for such analyses. Proteome-wide changes in newly identified biomarkers in tissues versus biofluids should then be pathobiochemically correlated. Subsequently new biomarker signatures have to be established in clinical laboratory practice for the superior evaluation of patient health status and the degree of skeletal muscular damage and contractile weakness. Ideally, longitudinal studies would be used to determine the robustness of new diagnostic markers and evaluate the modifying effects of routinely applied drug regimes, including pharmacological agents used in the supportive treatment of Duchenne patients, i.e. corticosteroids, beta blockers and angiotensin-converting-enzyme inhibitor. 
In the long-term, simple dot blot methods, standardized enzyme-linked immunosorbent assays, antibody arrays or miniaturized immunoblotting techniques have to be developed for routine diagnostic procedures. These assay systems should ideally test protein changes within a broad biomarker signature, which covers complex alterations due to tissue degeneration, reactive myofibrosis and sterile inflammation in the affected skeletal musculature, as well as secondary changes in the heart, liver, kidney and the central nervous system. Testing of proteomic markers can also be combined with non-proteinaceous molecules, such as extracellular microRNAs, lipids and/or metabolites. Noteworthy, fatty substitution in dystrophic muscles and ectopic fat depots in other organs due to muscular dystrophy has not been extensively researched by modern large-scale methodologies. Since alterations in a number of fatty acid binding protein isoforms have been described in various tissues and biofluids, it is of considerable interest to better understand abnormal fatty acid metabolism. The systematic proteomic screening of the liver, kidney and pancreas in combination with blood and urine samples could improve our understanding of secondary metabolic dysfunctions in dystrophinopathy. The standardization of biomarker assays will be especially crucial for the testing of new therapeutic approaches in the field of muscular dystrophy, such as stem cell therapy, utrophin substitution, steroid applications, stop codon read-through therapy, exon-skipping and CRISPR/ Cas9-related genome editing. Ideally new liquid biopsybased biomarker assays will be combined with conventional examination methods, such as strength tests and skeletal muscle imaging, for the improved diagnosis and prognosis of Duchenne muscular dystrophy.

\section{Funding}

This manuscript was supported by the Health Research Board (Ireland), Muscular Dystrophy Ireland, the Higher Education Authority (Ireland) and Maynooth University.

\section{Declaration of interest}

Kay Ohlendieck discloses research funding from the Health Research Board (Ireland), Muscular Dystrophy Ireland, the Higher Education Authority (Ireland). Sandra Murphy discloses Postgraduate Hume Scholarship from Maynooth University. The authors have no other relevant affiliations or financial involvement with any organization or entity with a financial interest in or financial conflict with the subject matter or materials discussed in the manuscript apart from those disclosed.

\section{Reviewers Disclosure}

Peer reviewers on this manuscript have no relevant financial relationships or otherwise to disclose.

\section{References}

Papers of special note have been highlighted as either of interest $(\cdot)$ or of considerable interest $(\cdot \bullet)$ to readers.
1. Cohen S, Nathan JA, Goldberg AL. Muscle wasting in disease: molecular mechanisms and promising therapies. Nat Rev Drug Discov. 2015;14:58-74.

2. Dowling JJ, Gonorazky H D, Cohn RD, et al. Treating pediatric neuromuscular disorders: the future is now. Am J Med Genet A. 2018;176:804-841.

- Helpful review on the importance of muscular disorders in paediatrics.

3. Dowling P, Murphy S, Ohlendieck K. Proteomic profiling of muscle fibre type shifting in neuromuscular diseases. Expert Rev Proteomics. 2016;13:783-799.

4. Landfeldt E, Edström J, Buccella F, et al. Duchenne muscular dystrophy and caregiver burden: a systematic review. Dev Med Child Neurol. 2018;60:987-996.

5. Guiraud S, Aartsma-Rus A, Vieira NM, et al. The Pathogenesis and Therapy of Muscular Dystrophies. Annu Rev Genomics Hum Genet. 2015;16:281-308.

6. Böhm SV, Roberts RG. Expression of members of the dystrophin, dystrobrevin, and dystrotelin superfamily. Crit Rev Eukaryot Gene Expr. 2009;19:89-108.

7. Murphy S, Dowling $P$, Zweyer M, et al. Proteomic profiling of giant skeletal muscle proteins. Expert Rev Proteomics. 2019;16:241-256.

8. Bladen $C L$, Salgado D, Monges $S$, et al. The TREAT-NMD DMD global database: analysis of more than 7,000 Duchenne muscular dystrophy mutations. Hum Mutat. 2015;36:395-402.

- Useful overview of the diverse types of mutations involved in dystrophinopathy.

9. Birnkrant DJ, Bushby K, Bann CM, et al. Diagnosis and management of Duchenne muscular dystrophy, part 1: diagnosis, and neuromuscular, rehabilitation, endocrine, and gastrointestinal and nutritional management. Lancet Neurol. 2018;17:251-267.

10. Coenen-Stass AML, Wood MJA, Roberts TC. Biomarker potential of extracellular mirnas in Duchenne muscular dystrophy. Trends Mol Med. 2017;23:989-1001.

11. Jungbluth $H$. Myopathology in times of modern imaging. Neuropathol Appl Neurobiol. 2017;43:24-43.

12. Szigyarto CA, Spitali P. Biomarkers of Duchenne muscular dystrophy: current findings. Degener Neurol Neuromuscul Dis. 2018;8:1-13.

13. Holland A, Carberry S, Ohlendieck K. Proteomics of the dystrophin-glycoprotein complex and dystrophinopathy. Curr Protein Pept Sci. 2013;14:680-697.

14. Fuller HR, Graham LC, Llavero Hurtado M, et al. Understanding the molecular consequences of inherited muscular dystrophies: advancements through proteomic experimentation. Expert Rev Proteomics. 2016;13:659-671.

15. Carr SJ, Zahedi RP, Lochmüller H, et al. Mass spectrometry-based protein analysis to unravel the tissue pathophysiology in Duchenne muscular dystrophy. Proteomics Clin Appl. 2018;12(2). DOI:10.1002/ prca.201700071

- Supplementary review files provide a useful list of new biomarker candidates.

16. Allen DG, Whitehead NP, Froehner SC. Absence of dystrophin disrupts skeletal muscle signaling: roles of $\mathrm{Ca} 2+$, reactive oxygen species, and nitric oxide in the development of muscular dystrophy. Physiol Rev. 2016;96(1):253-305.

17. Holland A, Murphy S, Dowling $P$, et al. Pathoproteomic profiling of the skeletal muscle matrisome in dystrophinopathy associated myofibrosis. Proteomics. 2016;16:345-366.

18. Tidball JG, Welc SS, Wehling-Henricks M. Immunobiology of inherited muscular dystrophies. Compr Physiol. 2018;8:1313-1356.

- Excellent review on the role of the immune system in muscle damage.

19. Klingler W, Jurkat-Rott K, Lehmann-Horn F, et al. The role of fibrosis in Duchenne muscular dystrophy. Acta Myol. 2012;31:184-195.

20. Desguerre I, Mayer M, Leturcq F, et al. Endomysial fibrosis in Duchenne muscular dystrophy: a marker of poor outcome 
associated with macrophage alternative activation. J Neuropathol Exp Neurol. 2009;68:762-773.

21. Serrano AL, Muñoz-Cánoves P. Fibrosis development in early-onset muscular dystrophies: mechanisms and translational implications. Semin Cell Dev Biol. 2017;64:181-190.

22. Crow RA, Hart KA, McDermott MP, et al. A checklist for clinical trials in rare disease: obstacles and anticipatory actions-lessons learned from the FOR-DMD trial. Trials. 2018;19:291.

23. Shimizu-Motohashi $Y$, Komaki $H$, Motohashi N, et al. Restoring dystrophin expression in Duchenne muscular dystrophy: current status of therapeutic approaches. J Pers Med. 2019;9:E1.

24. Min YL, Bassel-Duby R, Olson EN. CRISPR correction of Duchenne muscular dystrophy. Annu Rev Med. 2019;70:239-255.

25. Vila MC, Novak JS, Benny Klimek M, et al. Morpholino-induced exon skipping stimulates cell-mediated and humoral responses to dystrophin in mdx mice. J Pathol. 2019;248:339-351.

26. Wilson K, Faelan C, Patterson-Kane JC, et al. Duchenne and Becker muscular dystrophies: a review of animal models, clinical end points, and biomarker quantification. Toxicol Pathol. 2017;45:961-976.

27. Danko I, Chapman V, Wolff JA. The frequency of revertants in $\mathrm{mdx}$ mouse genetic models for Duchenne muscular dystrophy. Pediatr Res. 1992;32:128-131.

28. Deshmukh AS, Murgia M, Nagaraj N, et al. Deep proteomics of mouse skeletal muscle enables quantitation of protein isoforms, metabolic pathways, and transcription factors. Mol Cell Proteomics. 2015;14:841-853.

- Comprehensive reference databank of muscle-associated proteoforms.

29. Murgia M, Nagaraj N, Deshmukh AS, et al. Single muscle fiber proteomics reveals unexpected mitochondrial specialization. EMBO Rep. 2015;16:387-395.

30. Murphy S, Zweyer M, Raucamp M, et al. Proteomic profiling of the mouse diaphragm and refined mass spectrometric analysis of the dystrophic phenotype. J Muscle Res Cell Motil. 2019;40:9-28.

31. Capitanio D, Moriggi M, Gelfi C. Mapping the human skeletal muscle proteome: progress and potential. Expert Rev Proteomics. 2017;14:825-839.

32. Murphy $\mathrm{S}$, Ohlendieck $\mathrm{K}$. The biochemical and mass spectrometric profiling of the dystrophin complexome from skeletal muscle. Comput Struct Biotechnol J. 2015;14:20-27.

33. Constantin B. Dystrophin complex functions as a scaffold for signalling proteins. Biochim Biophys Acta. 2014;1838:635-642.

34. Lewis $C$, Ohlendieck K. Mass spectrometric identification of dystrophin isoform Dp427 by on-membrane digestion of sarcolemma from skeletal muscle. Anal Biochem. 2010;404:197-203.

35. Krieger CC, Bhasin N, Tewari M, et al. Exon-skipped dystrophins for treatment of Duchenne muscular dystrophy: mass spectrometry mapping of most exons and cooperative domain designs based on single molecule mechanics. Cytoskeleton (Hoboken). 2010;67:796-807.

36. Brown KJ, Marathi R, Fiorillo AA, et al. Accurate quantitation of dystrophin protein in human skeletal muscle using mass spectrometry. J Bioanal Biomed. 2012;(Suppl 7). DOI:10.4172/ 1948-593X.S7-001

37. Harrison R, Hitchen PG, Panico M, et al. Glycoproteomic characterization of recombinant mouse a-dystroglycan. Glycobiology. 2012;22:662-675.

38. Johnson EK, Zhang L, Adams ME, et al. Proteomic analysis reveals new cardiac-specific dystrophin-associated proteins. PLoS One. 2012;7:e43515.

39. Yoon $\mathrm{JH}$, Johnson $\mathrm{E}, \mathrm{Xu} \mathrm{R}$, et al. Comparative proteomic profiling of dystroglycan-associated proteins in wild type, $\mathrm{mdx}$, and Galgt2 transgenic mouse skeletal muscle. J Proteome Res. 2012;11:4413-4424.

40. Johnson EK, Li B, Yoon JH, et al. Identification of new dystroglycan complexes in skeletal muscle. PLoS One. 2013;8:e73224.
41. Turk R, Hsiao JJ, Smits MM, et al. Molecular signatures of membrane protein complexes underlying muscular dystrophy. Mol Cell Proteomics. 2016;15:2169-2185.

- Comprehensive biochemical and proteomic analysis of the dystrophin complex.

42. Murphy $S$, Brinkmeier $H$, Krautwald $M$, et al. Proteomic profiling of the dystrophin complex and membrane fraction from dystrophic $\mathrm{mdx}$ muscle reveals decreases in the cytolinker desmoglein and increases in the extracellular matrix stabilizers biglycan and fibronectin. J Muscle Res Cell Motil. 2017;38 (2):251-268.

43. Murphy S, Ohlendieck K. Mass spectrometric identification of dystrophin, the protein product of the Duchenne muscular dystrophy gene, in distinct muscle surface membranes. Int J Mol Med. 2017;40:1078-1088.

44. Murphy S, Zweyer M, Mundegar RR, et al. Chemical crosslinking analysis of beta-dystroglycan in dystrophin-deficient skeletal muscle. HRB Open Res. 2018;1:17.

45. Murphy $S$, Zweyer $M$, Henry $M$, et al. Proteomic analysis of the sarcolemma-enriched fraction from dystrophic mdx-4cv skeletal muscle. J Proteomics. 2019;191:212-227.

46. Ervasti JM, Ohlendieck K, Kahl SD, et al. Deficiency of a glycoprotein component of the dystrophin complex in dystrophic muscle. Nature. 1990;345:315-319.

47. Yoshida M, Ozawa E. Glycoprotein complex anchoring dystrophin to sarcolemma. J Biochem. 1990;108:748-752.

48. Ge Y, Molloy MP, Chamberlain JS, et al. Proteomic analysis of $\mathrm{mdx}$ skeletal muscle: great reduction of adenylate kinase 1 expression and enzymatic activity. Proteomics. 2003;3:1895-1903.

49. Doran P, Dowling P, Lohan J, et al. Subproteomics analysis of $\mathrm{Ca} 2$ +-binding proteins demonstrates decreased calsequestrin expression in dystrophic mouse skeletal muscle. Eur J Biochem. 2004;271:3943-3952.

50. Ge Y, Molloy MP, Chamberlain JS, et al. Differential expression of the skeletal muscle proteome in $\mathrm{mdx}$ mice at different ages. Electrophoresis. 2004;25:2576-2585.

51. Doran P, Martin G, Dowling P, et al. Proteome analysis of the dystrophin-deficient MDX diaphragm reveals a drastic increase in the heat shock protein cvHSP. Proteomics. 2006;6:4610-4621.

52. Doran P, Dowling P, Donoghue P, et al. Reduced expression of regucalcin in young and aged $\mathrm{mdx}$ diaphragm indicates abnormal cytosolic calcium handling in dystrophin-deficient muscle. Biochim Biophys Acta. 2006;1764:773-785.

53. Doran $P$, Wilton SD, Fletcher $S$, et al. Proteomic profiling of antisense-induced exon skipping reveals reversal of pathobiochemical abnormalities in dystrophic $\mathrm{mdx}$ diaphragm. Proteomics. 2009;9:671-685.

- Usage of proteomic biomarkers for the assessment of exon skipping therapy.

54. Lewis C, Ohlendieck K. Proteomic profiling of naturally protected extraocular muscles from the dystrophin-deficient $\mathrm{mdx}$ mouse. Biochem Biophys Res Commun. 2010;396:1024-1029.

55. Gardan-Salmon D, Dixon JM, Lonergan SM, et al. Proteomic assessment of the acute phase of dystrophin deficiency in mdx mice. Eur J Appl Physiol. 2011;111:2763-2773.

56. Guevel L, Lavoie JR, Perez-Iratxeta C, et al. Quantitative proteomic analysis of dystrophic dog muscle. J Proteome Res. 2011;10:2465-2478.

57. Lewis C, Doran P, Ohlendieck K. Proteomic analysis of dystrophic muscle. Methods Mol Biol. 2012;798:357-369.

58. Carberry S, Zweyer M, Swandulla D, et al. Proteomics reveals drastic increase of extracellular matrix proteins collagen and dermatopontin in the aged mdx diaphragm model of Duchenne muscular dystrophy. Int J Mol Med. 2012;30:229-234.

59. Carberry S, Zweyer M, Swandulla D, et al. Profiling of age-related changes in the tibialis anterior muscle proteome of the $\mathrm{mdx}$ mouse model of dystrophinopathy. J Biomed Biotechnol. 2012;2012:691641. 
60. Nghiem PP, Hoffman EP, Mittal P, et al. Sparing of the dystrophin-deficient cranial sartorius muscle is associated with classical and novel hypertrophy pathways in GRMD dogs. Am J Pathol. 2013;183:1411-1424.

61. Carberry S, Zweyer M, Swandulla D, et al. Application of fluorescence two-dimensional difference in-gel electrophoresis as a proteomic biomarker discovery tool in muscular dystrophy research. Biology (Basel). 2013;2:1438-1464.

62. Rayavarapu S, Coley W, Cakir E, et al. Identification of disease specific pathways using in vivo SILAC proteomics in dystrophin deficient mdx mouse. Mol Cell Proteomics. 2013;12:1061-1073.

- SILAC-based proteomics applied to studying the dystrophic phenotype.

63. Carberry $\mathrm{S}$, Brinkmeier $\mathrm{H}$, Zhang $\mathrm{Y}$, et al. Comparative proteomic profiling of soleus, extensor digitorum longus, flexor digitorum brevis and interosseus muscles from the $\mathrm{mdx}$ mouse model of Duchenne muscular dystrophy. Int J Mol Med. 2013;32:544-556.

64. Matsumura $C Y$, Menezes de Oliveira B, Durbeej $M$, et al. Isobaric tagging-based quantification for proteomic analysis: a comparative study of spared and affected muscles from mdx mice at the early phase of dystrophy. PLoS One. 2013;8:e65831.

65. Carberry S, Zweyer M, Swandulla D, et al. Comparative proteomic analysis of the contractile-protein-depleted fraction from normal versus dystrophic skeletal muscle. Anal Biochem. 2014;446:108-115.

66. Holland A, Dowling P, Meleady $P$, et al. Label-free mass spectrometric analysis of the $m d x-4 c v$ diaphragm identifies the matricellular protein periostin as a potential factor involved in dystrophinopathy-related fibrosis. Proteomics. 2015;15:2318-2331.

67. Holland A, Henry M, Meleady $P$, et al. Comparative label-free mass spectrometric analysis of mildly versus severely affected $\mathrm{mdx}$ mouse skeletal muscles identifies annexin, lamin, and vimentin as universal dystrophic markers. Molecules. 2015;20:11317-11344.

68. Roberts TC, Johansson HJ, McClorey G. Multi-level omics analysis in a murine model of dystrophin loss and therapeutic restoration. Hum Mol Genet. 2015;24:6756.

- Extensive listing of proteomic markers of muscular dystrophy

69. Murphy S, Henry M, Meleady P, et al. Simultaneous pathoproteomic evaluation of the dystrophin-glycoprotein complex and secondary changes in the mdx-4cv mouse model of Duchenne muscular dystrophy. Biology (Basel). 2015;4:397-423.

70. Fontana S, Schillaci O, Frinchi $\mathrm{M}$, et al. Reduction in $\mathrm{mdx}$ mouse muscle degeneration by low-intensity endurance exercise: a proteomic analysis in quadriceps muscle of exercised compared with sedentary mdx mice. Biosci Rep. 2015;35:e00213.

71. Murphy S, Zweyer M, Mundegar RR, et al. Concurrent label-free mass spectrometric analysis of dystrophin isoform Dp427 and the myofibrosis marker collagen in crude extracts from mdx-4cv skeletal muscles. Proteomes. 2015;3:298-327.

72. Lardenois $A$, Jagot $S$, Lagarrigue $M$, et al. Quantitative proteome profiling of dystrophic dog skeletal muscle reveals a stabilized muscular architecture and protection against oxidative stress after systemic delivery of MuStem cells. Proteomics. 2016;16:2028-2042.

73. Arecco N, Clarke CJ, Jones FK, et al. Elastase levels and activity are increased in dystrophic muscle and impair myoblast cell survival, proliferation and differentiation. Sci Rep. 2016;6:24708.

74. Fröhlich T, Kemter E, Flenkenthaler $F$, et al. Progressive muscle proteome changes in a clinically relevant pig model of Duchenne muscular dystrophy. Sci Rep. 2016;6:33362.

75. Vila MC, Rayavarapu S, Hogarth MW, et al. Mitochondria mediate cell membrane repair and contribute to Duchenne muscular dystrophy. Cell Death Differ. 2017;24:330-342.

76. Murphy $S$, Zweyer $M$, Henry $M$, et al. Subproteomic profiling of sarcolemma from dystrophic mdx-4cv skeletal muscle. Data Brief. 2018;17:980-993.

77. Murphy S, Zweyer M, Mundegar RR, et al. Comparative gel-based proteomic analysis of chemically crosslinked complexes in dystrophic skeletal muscle. Electrophoresis. 2018;39:1735-1744.
78. Gamberi T, Fiaschi T, Valocchia E, et al. Proteome analysis in dystrophic $\mathrm{mdx}$ mouse muscle reveals a drastic alteration of key metabolic and contractile proteins after chronic exercise and the potential modulation by anti-oxidant compounds. J Proteomics. 2018;170:43-58.

79. Gulston MK, Rubtsov DV, Atherton $\mathrm{HJ}$, et al. A combined metabolomic and proteomic investigation of the effects of a failure to express dystrophin in the mouse heart. J Proteome Res. 2008;7:2069-2077.

80. Lewis $\mathrm{C}$, Jockusch $\mathrm{H}$, Ohlendieck K. Proteomic profiling of the dystrophin-deficient MDX heart reveals drastically altered levels of key metabolic and contractile proteins. J Biomed Biotechnol. 2010;2010:648501.

81. Holland A, Dowling $P$, Zweyer $M$, et al. Proteomic profiling of cardiomyopathic tissue from the aged mdx model of Duchenne muscular dystrophy reveals a drastic decrease in laminin, nidogen and annexin. Proteomics. 2013;13:2312-2323.

82. Murphy $S$, Zweyer M, Henry M, et al. Label-free mass spectrometric analysis reveals complex changes in the brain proteome from the $m d x-4 c v$ mouse model of Duchenne muscular dystrophy. Clin Proteomics. 2015;12:27.

83. Zhang A, Uaesoontrachoon K, Shaughnessy C, et al. The use of urinary and kidney SILAM proteomics to monitor kidney response to high dose morpholino oligonucleotides in the $\mathrm{mdx}$ mouse. Toxicol Rep. 2015;2:838-849.

84. Murphy S, Dowling $\mathrm{P}$, Zweyer $\mathrm{M}$, et al. Proteomic analysis of dystrophin deficiency and associated changes in the aged $\mathrm{mdx}-4 \mathrm{cv}$ heart model of dystrophinopathy-related cardiomyopathy. J Proteomics. 2016;145:24-36.

85. Murphy $S$, Zweyer M, Henry $M$, et al. Proteomic profiling of liver tissue from the $m d x-4 c v$ mouse model of Duchenne muscular dystrophy. Clin Proteomics. 2018;15:34.

- Identification of abnormal liver metabolism in the dystrophic phenotype.

86. Murphy S, Ohlendieck K. Proteomic profiling of the dystrophin-deficient brain. Methods Mol Biol. 2018;1687:91-105.

87. Murphy S, Zweyer M, Mundegar RR, et al. Proteomic serum biomarkers for neuromuscular diseases. Expert Rev Proteomics. 2018;15:277-291.

88. Sanchez-Carbayo M. Antibody microarrays as tools for biomarker discovery. Methods Mol Biol. 2011;785:159-182.

89. McKay HS, Margolick JB, Martínez-Maza O, et al. Multiplex assay reliability and long-term intra-individual variation of serologic inflammatory biomarkers. Cytokine. 2017;90:185-192.

90. Mustafa SA, Hoheisel JD, Alhamdani MS. Secretome profiling with antibody microarrays. Mol Biosyst. 2011;7:1795-1801.

91. Ayoglu B, Chaouch A, Lochmüller $H$, et al. Affinity proteomics within rare diseases: a BIO-NMD study for blood biomarkers of muscular dystrophies. EMBO Mol Med. 2014;6:918-936.

- Comprehensive array of new serum markers of dystrophinopathy.

92. Ho PP, Lahey L, Mourkioti F, et al. Engineered DNA plasmid reduces immunity to dystrophin while improving muscle force in a model of gene therapy of Duchenne dystrophy. Proc Natl Acad Sci USA. 2018;115:E9182-E9191.

93. Mueller C, Liotta LA, Espina V. Reverse phase protein microarrays advance to use in clinical trials. Mol Oncol. 2010;4:461-481.

94. Escher $\mathrm{C}$, Lochmüller $\mathrm{H}$, Fischer $\mathrm{D}$, et al. Reverse protein arrays as novel approach for protein quantification in muscular dystrophies. Neuromuscul Disord. 2010;20:302-309.

95. Alagaratnam S, Mertens BJ, Dalebout JC, et al. Serum protein profiling in mice: identification of factor XIIla as a potential biomarker for muscular dystrophy. Proteomics. 2008;8:1552-1563.

96. Colussi C, Banfi C, Brioschi M, et al. Proteomic profile of differentially expressed plasma proteins from dystrophic mice and following suberoylanilide hydroxamic acid treatment. Proteomics Clin Appl. 2010;4:71-83.

97. Duguez S, Duddy W, Johnston H, et al. Dystrophin deficiency leads to disturbance of LAMP1-vesicle-associated protein secretion. Cell Mol Life Sci. 2013;70:2159-2174. 
98. Cynthia Martin F, Hiller M, Spitali $P$, et al. Fibronectin is a serum biomarker for Duchenne muscular dystrophy. Proteomics Clin Appl. 2014;8:269-278.

99. Rouillon J, Zocevic A, Leger T, et al. Proteomics profiling of urine reveals specific titin fragments as biomarkers of Duchenne muscular dystrophy. Neuromuscul Disord. 2014;24:563-573.

100. Hathout Y, Marathi RL, Rayavarapu S, et al. Discovery of serum protein biomarkers in the $\mathrm{mdx}$ mouse model and cross-species comparison to Duchenne muscular dystrophy patients. Hum Mol Genet. 2014;23:6458-6469.

101. Rouillon J, Poupiot J, Zocevic A, et al. Serum proteomic profiling reveals fragments of MYOM3 as potential biomarkers for monitoring the outcome of therapeutic interventions in muscular dystrophies. Hum Mol Genet. 2015;24:4916-4932.

102. Coenen-Stass AM, McClorey G, Manzano R, et al. Identification of novel, therapy-responsive protein biomarkers in a mouse model of Duchenne muscular dystrophy by aptamer-based serum proteomics. Sci Rep. 2015;5:17014.

103. Hathout $Y$, Brody $E$, Clemens PR, et al. Large-scale serum protein biomarker discovery in Duchenne muscular dystrophy. Proc Natl Acad Sci USA. 2015;112:7153-7158.

104. Oonk S, Spitali $P$, Hiller $M$, et al. Comparative mass spectrometric and immunoassay-based proteome analysis in serum of Duchenne muscular dystrophy patients. Proteomics Clin Appl. 2016;10:290-299.

105. Hathout $\mathrm{Y}$, Seol $\mathrm{H}$, Han $\mathrm{MH}$, et al. Clinical utility of serum biomarkers in Duchenne muscular dystrophy. Clin Proteomics. 2016;13:9.

106. Murphy S, Dowling P, Zweyer M, et al. Proteomic profiling of $m d x-4 c v$ serum reveals highly elevated levels of the inflammation-induced plasma marker haptoglobin in muscular dystrophy. Int J Mol Med. 2017;39:1357-1370.

107. Guiraud S, Edwards B, Squire SE, et al. Identification of serum protein biomarkers for utrophin based DMD therapy. Sci Rep. 2017;7:43697.
108. Burch PM, Pogoryelova O, Palandra J, et al. Reduced serum myostatin concentrations associated with genetic muscle disease progression. J Neurol. 2017;264:541-553.

109. Spitali P, Hettne K, Tsonaka R, et al. Tracking disease progression non-invasively in Duchenne and Becker muscular dystrophies. J Cachexia Sarcopenia Muscle. 2018;9:715-726.

110. Murphy S, Zweyer M, Mundegar RR, et al. Dataset on the comparative proteomic profiling of mouse saliva and serum from wild type versus the dystrophic $\mathrm{mdx}-4 \mathrm{cv}$ mouse model of dystrophinopathy. Data Brief. 2018;21:1236-1245.

111. Parolo S, Marchetti L, Lauria $M$, et al. Combined use of protein biomarkers and network analysis unveils deregulated regulatory circuits in Duchenne muscular dystrophy. PLoS One. 2018;13:e0194225.

112. Gao X, Tang Y, Amra S, et al. Systemic investigation of bone and muscle abnormalities in dystrophin/utrophin double knockout mice during postnatal development and the mechanisms. Hum Mol Genet. 2019;28:1738-1751.

113. Murphy S, Zweyer M, Mundegar RR, et al. Proteomic identification of elevated saliva kallikrein levels in the $\mathrm{mdx}-4 \mathrm{cv}$ mouse model of Duchenne muscular dystrophy. Biochem Biophys Rep. 2019;18:100541.

114. Conklin LS, Merkel PA, Pachman LM, et al. Serum biomarkers of glucocorticoid response and safety in anti-neutrophil cytoplasmic antibody-associated vasculitis and juvenile dermatomyositis. Steroids. 2018;140:159-166.

115. Hathout Y, Conklin LS, Seol H, et al. Serum pharmacodynamic biomarkers for chronic corticosteroid treatment of children. Sci Rep. 2016;6:31727.

116. Cruz-Guzmán Odel R, Rodríguez-Cruz M, Escobar Cedillo RE. Systemic inflammation in Duchenne muscular dystrophy: association with muscle function and nutritional status. Biomed Res Int. 2015;2015:891972.

117. Rodríguez-Cruz M, Cruz-Guzmán OR, Escobar RE, et al. Leptin and metabolic syndrome in patients with Duchenne/Becker muscular dystrophy. Acta Neurol Scand. 2016;133:253-260. 